\title{
GRACE constraints on Earth rheology of the Barents Sea and Fennoscandia
}

\author{
Marc Rovira-Navarro ${ }^{1,2}$, Wouter van der Wal ${ }^{1,3}$, Valentina R. Barletta ${ }^{4}$, Bart C. Root $^{1}$, and \\ Louise Sandberg Sørensen ${ }^{4}$ \\ ${ }^{1}$ Faculty of Aerospace Engineering, TU Delft, Building 62 Kluyverweg 1, 2629 HS Delft, the Netherlands \\ ${ }^{2}$ NIOZ Royal Netherlands Institute for Sea Research, Department of Estuarine and Delta Systems EDS, and Utrecht \\ University, P.O. Box 140, 4400 AC Yerseke, the Netherlands \\ ${ }^{3}$ Faculty of Civil Engineering and Geosciences, TU Delft, Stevinweg 1, 2628 CN Delft, the Netherlands \\ ${ }^{4}$ National Space Institute, DTU Space, Technical University of Denmark, Elektrovej Bygning 327, \\ 2800 Kongens Lyngby, Denmark
}

Correspondence: Marc Rovira-Navarro (marc.rovira@nioz.nl)

Received: 4 June 2019 - Discussion started: 13 June 2019

Revised: 6 February 2020 - Accepted: 17 February 2020 - Published: 26 March 2020

\begin{abstract}
The Barents Sea is situated on a continental margin and was home to a large ice sheet at the Last Glacial Maximum. Studying the solid Earth response to the removal of this ice sheet (glacial isostatic adjustment; GIA) can give insight into the subsurface rheology of this region. However, because the region is currently covered by ocean, uplift measurements from the center of the former ice sheet are not available. The Gravity Recovery and Climate Experiment (GRACE) gravity data have been shown to be able to constrain GIA. Here we analyze GRACE data for the period 2003-2015 in the Barents Sea and use the data to constrain GIA models for the region. We study the effect of uncertainty in non-tidal ocean mass models that are used to correct GRACE data and find that it should be taken into account when studying solid Earth signals in oceanic areas from GRACE. We compare GRACE-derived gravity disturbance rates with GIA model predictions for different ice deglaciation chronologies of the last glacial cycle and find that best-fitting models have an upper mantle viscosity equal or higher than $3 \times 10^{20} \mathrm{Pas}$. Following a similar procedure for Fennoscandia we find that the preferred upper mantle viscosity there is a factor 2 larger than in the Barents Sea for a range of lithospheric thickness values. This factor is shown to be consistent with the ratio of viscosities derived for both regions from global seismic models. The viscosity difference can serve as constraint for geodynamic models of the area.
\end{abstract}

\section{Introduction}

Ongoing viscous rebound of the solid Earth (glacial isostatic adjustment; GIA) after the collapse of large ice sheets results in positive gravity disturbance rates in several regions of the Earth. The Gravity Recovery and Climate Experiment (GRACE) satellite data have been used to constrain numerical models for GIA in North America (Tamisiea et al., 2007; Paulson et al., 2007; van der Wal et al., 2008; Sasgen et al., 2012) and Fennoscandia (Steffen and Denker, 2008; van der Wal et al., 2011; Simon et al., 2018). With longer time series it is now possible to observe weaker GIA signals such as that of the Svalbard-Barents-Kara Ice Sheet (SBKIS) in GRACE gravity data (Root et al., 2015a; Kachuck and Cathles, 2018; Simon et al., 2018). The use of GRACE data is especially relevant in this region as other geodetic observations normally used for GIA studies are only available from the islands surrounding the Barents Sea, in the periphery of the ice sheet that covered the region during the Last Glacial Maximum (LGM). This makes GIA-based ice sheet reconstructions such as ICE-5G and ICE-6G (Peltier, 2004; Peltier et al., 2015; Argus et al., 2014) uncertain.

Earlier work on the SBKIS proposed the existence of an extensive ice sheet spanning from the British Isles to the Kara Sea and extending further into mainland Russia (e.g., Grosswald, 1980, 1998), but more recent studies favor a smaller ice sheet (e.g., Lambeck, 1995; Siegert and Dowdeswell, 1995; Svendsen et al., 1999, 2004; Mangerud et al., 2002). During 
the last decade, more geological and glaciological observations relevant for reconstructing the SBKIS have been obtained and compiled in the first version of the DATabase of Eurasian Deglaciation (DATED-1), resulting in new ice sheet limits for the whole Eurasian Ice Sheet Complex (EISC) (Hughes et al., 2016), but ice thickness variations cannot be uniquely established.

Comparing the GRACE-derived gravity disturbance rates with those predicted for different paleo-ice sheet configurations, Root et al. (2015a) conclude that the SBKIS contained less ice than previously thought. Kachuck and Cathles (2018) use GRACE data, along with relative sea level (RSL) curves and GPS uplift measurements, to distinguish between two deglaciation histories: one with an ice sheet with a central dome in the Barents Sea and one with the Barents Sea marginally glaciated and domes in the surrounding Arctic islands. They show that the data are inconclusive in this regard.

Since the gravity disturbance rate signal in the Barents Sea region is small, it is important to thoroughly analyze the uncertainty in GRACE data. Here we present an extended analysis of GRACE data in the region and the different uncertainty sources. We focus on the gravity disturbance rate due to non-tidal mass variations in the ocean, which influence the secular signal from GRACE data in oceanic areas (de Linage et al., 2009). In the processing chain to obtain Level 2 GRACE data, changes in ocean-bottom pressure are removed using the Ocean Model for Circulation and Tides (OMCT) forced with atmospheric data from the European Centre for Medium-Range Weather Forecasts (ECMWF). However, the OMCT secular signal is not reliable and should not be interpreted geophysically (Dobslaw et al., 2013). Lemoine et al. (2007) used a different ocean model in their GRACE data processing and found significant differences in the southern Arctic ocean.

We compare GRACE-derived gravity disturbance rates to GIA model output to constrain the input of the GIA model. Because of uncertainty in solid Earth parameters and deglaciation history, it is difficult to uniquely constrain both. However, we can compare the GIA models for the Barents and Kara Sea areas with models for Fennoscandia constrained by the same data. In this way we can determine if there is a difference in Earth properties for both regions that is systematic for all deglaciation chronologies. Such constraints on variation in viscosity are useful for GIA modeling and geodynamic modeling in general, as viscosity maps derived from laboratory experiments and seismic velocities are not sufficiently constrained (e.g., Barnhoorn et al., 2011). Furthermore, the Barents Sea is located on a continental margin, and knowledge of the subsurface rheology can help decipher its tectonic history. Our aim is to provide a constraint on upper mantle viscosity for the Barents Sea region and Fennoscandia, focusing on the difference in viscosity between the two regions. We build on existing knowledge of Earth rheology and ice histories, which will be briefly reviewed in the following.
The rheology of the Barents Sea region is expected to be different from that of Fennoscandia, as it borders passive oceanic margins in the north and the west. Seismic tomography reveals lower seismic velocities in Barents Sea than below Fennoscandia (Levshin et al., 2007; Schaeffer and Lebedev, 2013) but not for all seismic periods and depths. 3D viscosity profiles have been implemented in GIA models for the regions and have been found to affect sea level and uplift rates (Kaufmann and Wu, 1998). However, the difference in properties between Fennoscandia and Barents Sea has not been studied explicitly.

Constraints from palaeoshoreline data on 1D GIA models resulted in best-fitting upper mantle viscosities of 2-6x $10^{20} \mathrm{Pas}$ in the Barents Sea region (Steffen and Kaufmann, 2005), while recent work based on RSL data finds that the best-fitting upper mantle viscosity in the Barents Sea region is above $2 \times 10^{20} \mathrm{Pas}$ (Auriac et al., 2016). For Fennoscandia, the best-fitting upper mantle viscosity is found to be between 3 and $7 \times 10^{20} \mathrm{Pas}$ based on RSL data and relaxation time spectra, while best-fitting models based on GPS uplift rate measurements have upper mantle viscosities up to $15 \times 10^{20} \mathrm{Pas}$; see the overview in Steffen and Wu (2011). More recent work summarized in Simon et al. (2018) shows an upper mantle viscosity in the range of $3.4-20 \times 10^{20} \mathrm{Pas}$. Note that the lower bound for upper mantle viscosity in the Barents Sea is somewhat below that in Fennoscandia. Steffen and Kaufmann (2005) computed RSL misfit and find similar upper mantle viscosity for the Barents Sea and the Scandinavian mainland but smaller lower mantle viscosity. However, the different studies used different ice histories and relied on multiple data sources, with substantially less coverage in the Barents Sea region. Therefore it is unknown if it can be concluded from previous 1D studies whether viscosity is indeed lower in the Barents Sea than in Fennoscandia.

In this study we analyze GRACE data in the Barents Sea region and Fennoscandia in order to obtain the GIA signal there, focusing on the first region where the signal-to-noise ratio is lower. We compare the estimated signal with 1D GIA model output to infer upper or lower bounds in viscosity for different ice deglaciation chronologies. From comparison between the best-fitting models for the two regions we draw conclusions on the variation in Earth rheology between the Barents Sea and Fennoscandia.

\section{Methodology}

\subsection{GRACE data processing}

Temporal variations in the Earth's gravity field measured by GRACE are related to mass transport within the Earth system due to different geophysical processes, such as hydrology, ongoing cryospheric mass changes, GIA and (post-) seismic signals (e.g., Wouters et al., 2014). To study GIA, other geophysical signals that mask the GIA signal should 
be removed. Additionally, GRACE data are affected by instrumental noise and the anisotropic sampling of the signal due to the orbit of the satellites (Wahr, 2007; Flechtner et al., 2016). Different data-processing techniques have been developed to increase the GRACE signal-to-noise ratio (e.g., Han et al., 2005; Swenson and Wahr, 2006; Kusche et al., 2009). In the following, we detail the postprocessing used to analyze GRACE data in the Barents Sea and Fennoscandia, with a focus on the Barents Sea as it presents additional difficulties due to the smaller magnitude of the signal.

In our analysis we use the University of Texas Center for Space Research (UTCSR) release 5 (RL05) (Bettadpur, 2012) up to spherical harmonic degree 60 . The difference between GRACE solutions up to degree 96 and degree 60 is shown to mainly manifest as north-south oriented stripes characteristic of the high-frequency noise in GRACE, with a magnitude at the noise level (Sakumura, 2014); therefore we do not use the coefficients beyond degree 60. Furthermore, their influence would be reduced because of the filtering that is applied in our processing as explained later in this section. We use data for the 2003-2015 period. We substitute the degree 2 coefficients with those obtained from satellite laser ranging (Cheng et al., 2013). We use the leastsquares method to obtain the secular, annual and semiannual signals of each time series of Stokes coefficients. We estimate GRACE measurement errors $\left(\sigma_{\mathrm{GRACE}}\right)$ using the residuals after the secular, annual and semiannual signals are removed from the signal (Wahr et al., 2006).

After processing the signal as explained above, the GIA signal is evident as a positive gravity rate in Fennoscandia and the Barents Sea (Fig. 1a). However, the signal is contaminated by the correlated noise in the higher-degree GRACE data; this is evident as north-south oriented stripes. We use a Gaussian filter to filter out short-wavelength noise and apply the same filters and maximum spherical harmonic degree to the GIA model output. The choice for filter half width affects the signal-to-noise ratio. Earlier studies in Scandinavia used a $400 \mathrm{~km}$ half width Gaussian filter (e.g., Steffen and Denker, 2008; van der Wal et al., 2011), but the better accuracy of later GRACE data releases and longer time series since then allow less filtering. To account for the fact that the optimum filter half width is not known, we adopt a range of high-pass filter half widths from 200 to $300 \mathrm{~km}$. At $200 \mathrm{~km}$ half width correlated noise (stripes) are still visible (Fig. 1a, b), while for filter half widths larger than $300 \mathrm{~km}$ the positive gravity anomaly in the Barents Sea is very small (Fig. 2). Low-pass filtering to reduce the measurement noise inevitably means that some sensitivity to possible high-frequency signal content in the GIA models is lost; that is, we cannot assess detailed changes in ice thickness based on our GRACE gravity rates. We additionally use a high-pass filter in the Barents Sea to remove the long-wavelength signal that contains longwavelength phenomena such as global sea level rise that are not modeled. The high-pass filter half width ranges from 500 to $700 \mathrm{~km}$, which was found to be optimal to remove long- wavelength signals while retaining most of the SBKIS GIA signal (see Root et al., 2015a, Supporting Information). As the signal in Fennoscandia is larger and has a larger wavelength we only use the low-pass filter there with a half width that also ranges from 200 to $300 \mathrm{~km}$.

The total observed gravity signal (Fig. 1a, b, d) cannot be directly interpreted as the GIA footprint of the paleo-ice sheet as it contains the trend of other geophysical processes as well, one of them being hydrology. Secular changes in land water storage result in gravity trends that should be subtracted when analyzing GRACE data in continental areas. The long-term hydrology signal in Fennoscandia is probably small, as demonstrated by the good agreement between GIA signals derived from GRACE and GPS (van der Wal et al., 2011). However, the hydrology signal of the Russian Arctic archipelago (Novaya Zemlya, Franz Josef Land and Severnaya Zemlya) can leak into oceanic areas. We subtract the hydrology signal using the GLDAS hydrology model (Rodell et al., 2004). Because its reliability for the islands of the Russian Arctic archipelago is not well known, we follow Matsuo and Heki (2013) and take the amplitude of its trend in the Barents Sea as an indication of the uncertainty in the hydrology signal in these polar regions ( $\left.\sigma_{\text {hydrology }}\right)$.

Present-day changes in the cryosphere and the resulting present-day solid Earth response can also mask the GIA signal. In particular, the glaciers of the islands of Svalbard and the Russian Arctic archipelago are experiencing significant mass changes evident in GRACE observations, which partly mask the GIA signal in the Barents Sea region (see Fig. 1). Independent data on mass changes in Svalbard and the Russian Arctic archipelago are limited. Moholdt et al. (2012) derived trends using ICESat for the 2003-2009 period using altimetry; other authors (e.g., Schrama et al., 2014; Matsuo and Heki, 2013) have used GRACE data. For the period 2003-2008, GRACE estimates are lower than altimetry estimates but agree within uncertainty (Root et al., 2015a). In Simon et al. (2018) ice mass loss estimates from altimetry and glaciology for a longer period were shown to be much larger than GRACE estimates in Svalbard, Franz Josef Land and Novaya Zemlya, and altimetry estimates were scaled down in that study. Here we follow Root et al. (2015a) and use ice loss corrections obtained using the mascon method of Schrama et al. (2014) (see Table 1) to remove the ice loss signal taking into account elastic loading (Wahr et al., 1998).

To obtain the present-day mass changes from GRACE, a GIA correction needs to be first applied As our aim is to quantify the GIA signal in the central Barents Sea, the problem seems circular. However, the GIA model has a relatively small effect on the derived present-day mass changes. We account for uncertainty in mass loss estimations due to GIA by employing an ensemble of ice deglaciation chronologies and Earth rheological parameters. We use the ICE-5G model and two runs of the GSM ice model (Tarasov et al., 2012) with maximum and minimum ice sheet extents combined with the VM5a Earth model (Peltier, 2004) and an Earth model with a 


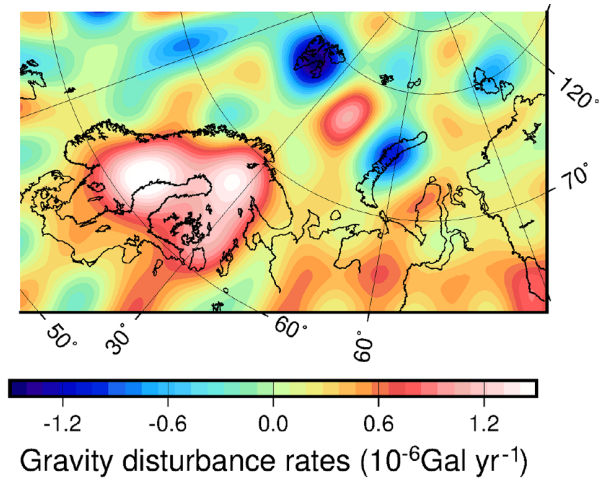

(a)

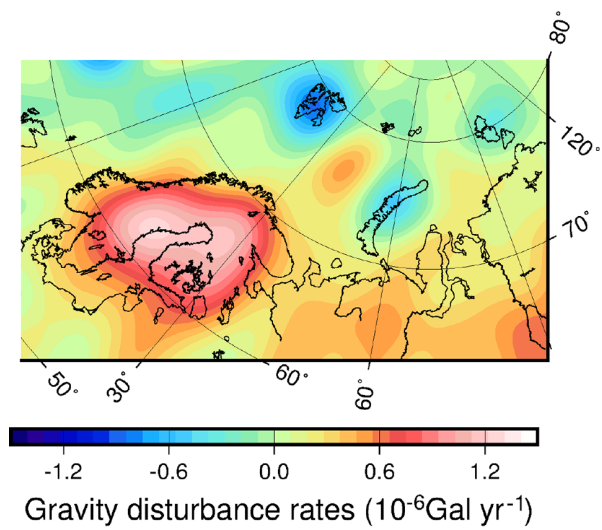

(b)

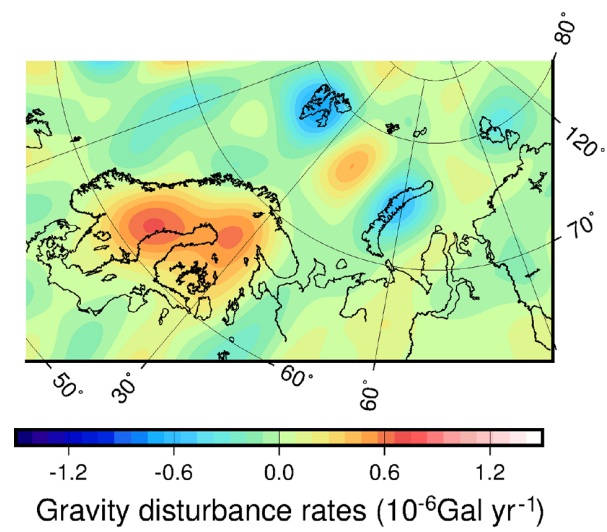

(d)

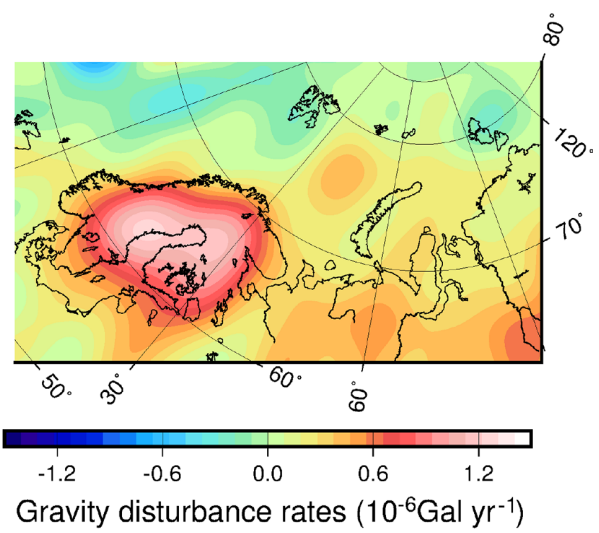

(c)

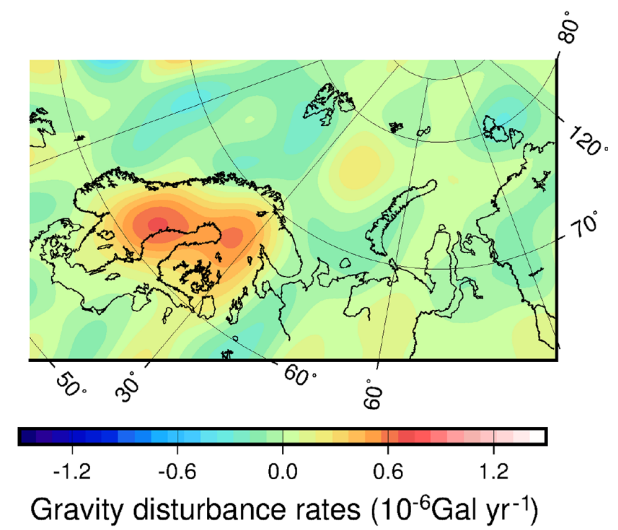

(e)

Figure 1. Gravity signal in Fennoscandia and the Barents Sea for the period 2003-2015. Panel (a) shows the gravity disturbance trends for the unprocessed GRACE data. Panels (b) and (c) show the gravity disturbance rate filtered with a $200 \mathrm{~km}$ low-pass filter, while in (d) and (e) the data are additionally filtered with a $600 \mathrm{~km}$ high-pass filter to remove long-wavelength signals. The mass loss signal of the Russian Arctic archipelago islands has been removed in (c) and (e).

stronger mantle, as well as the W12 ice model (Whitehouse et al., 2012) with a strong mantle. Mass loss changes obtained using the different GIA models are shown in Table 1; more massive ice sheet models and stronger mantles result in higher mass loss rates. The error in the derived mass changes due to uncertainty in GIA is similar to the GRACE measurement error. We use the error bars of the estimated mass changes for Svalbard and the Russian Arctic archipelago to estimate the error in the recovered GIA gravity rates due to uncertainty in mass loss changes in the region $\left(\sigma_{\text {ice }}\right)$. Finally, 


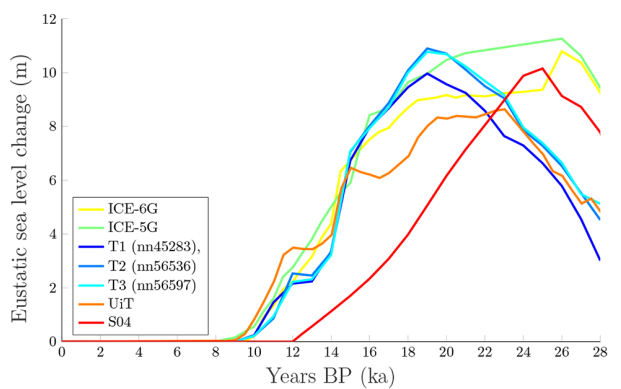

(a) SIS

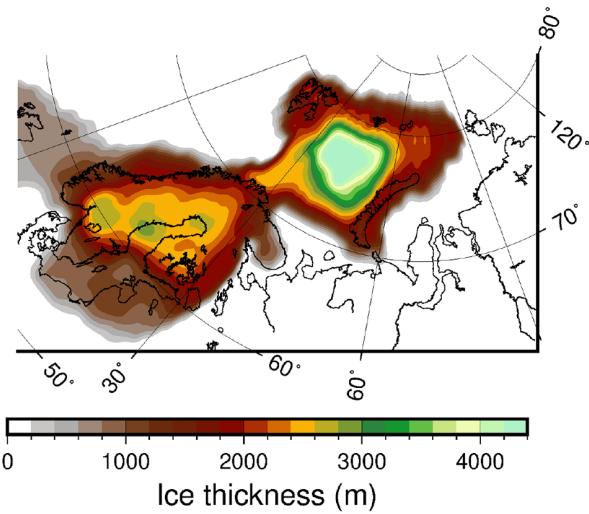

(c) ICE-6G, 25 ka

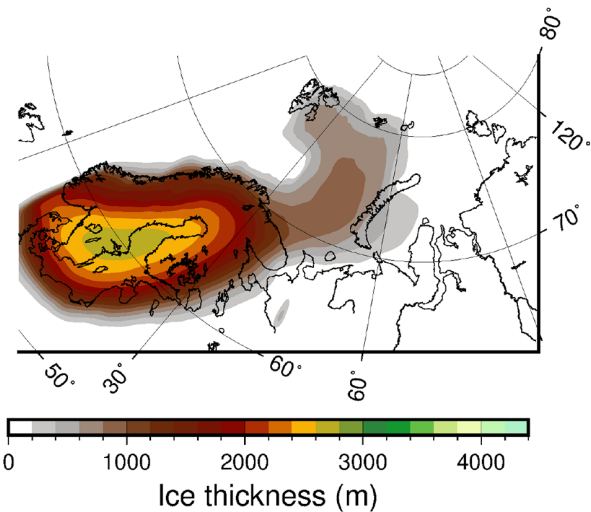

(e) S04, $25 \mathrm{ka}$

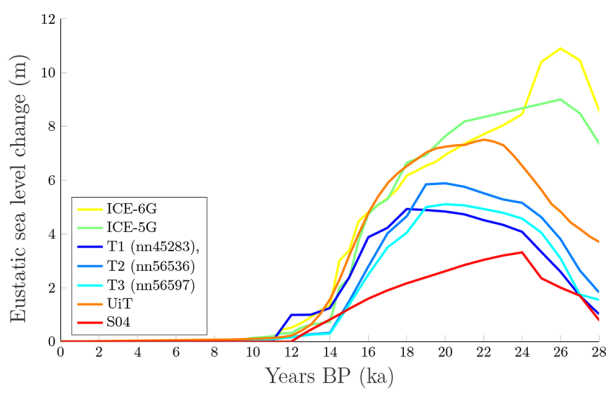

(b) SBKIS

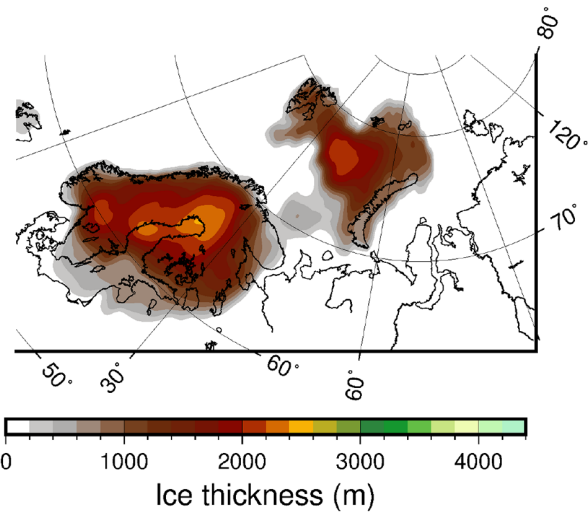

(d) ICE-6G, $15 \mathrm{ka}$

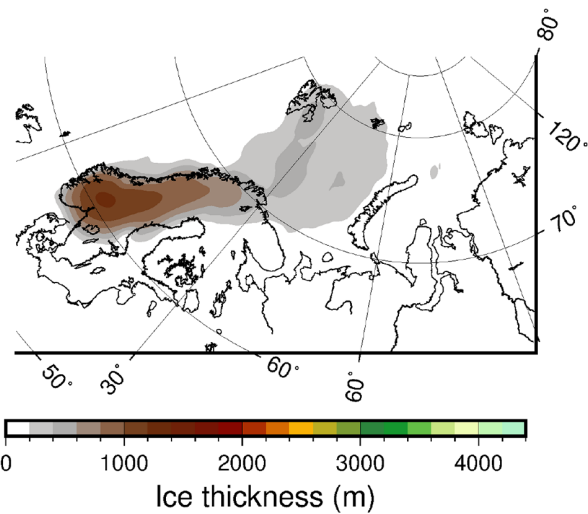

(f) $\mathrm{S} 04,15 \mathrm{ka}$

Figure 2. Volume of ice present in the (a) SIS and (b) SBKIS during the last glacial period, given in equivalent eustatic sea level rise for different ice sheet reconstructions. Six different deglaciation chronologies are shown, including the following: the GIA-constrained models ICE-5G and ICE-6G (Peltier, 2004; Peltier et al., 2015; Argus et al., 2014); three models obtained using the Glacial System Model (GSM) (Tarasov et al., 2012), the T1, T2 and T3 chronologies; the University of Tromsø Ice Sheet Model (UiT) (Patton et al., 2017); and the S04 ice sheet model (Siegert and Dowdeswell, 2004). The divide between both ice sheets is taken to be the $70^{\circ}$ parallel. Ice extent and thickness are shown for the (c, d) ICE-6G and (e, f) S04 ice models for two different epochs.

for the Barents Sea, the Greenland mass loss is already filtered when using the high-pass filter, but for Fennoscandia we need to remove it. To do so we use ICESat mass changes from Sørensen et al. (2011).

We account for the uncertainty in non-tidal ocean changes by using the ECCO ocean model (Forget et al., 2015) as alternative for the ocean model used in standard GRACE level 2 processing. In that case we first add back the GAB prod- ucts (monthly non-tidal oceanic mass anomalies simulated by the OMCT ocean model) to restore the full GRACE ocean mass signal (Flechtner et al., 2015; Yu et al., 2018) before subtracting the ECCO ocean model. The ECCO model is a dynamically consistent ocean model constrained with observations from altimetry, Argo floats and GRACE. The model has been shown to correctly capture long-term bottom pressure variability in the Arctic Ocean and adjacent 
Table 1. Ice loss changes in Svalbard and the islands of the Russian Arctic archipelago between 2003 and 2015 in Gtyr ${ }^{-1}$, obtained for different GIA models. The ICE-5G model and two runs of the GSM with maximum (GLAC2) and minimum (GLAC1) ice sheet extents, which comply with RSL and GPS observations combined with the VM5 Earth rheological model or a model with stronger mantle, labeled $\mathrm{M} 2$, with $\mu_{\mathrm{UM}}=1.6 \times 10^{21} \mathrm{Pas}$ and $\mu_{\mathrm{LM}}=5.12 \times 10^{22} \mathrm{Pas}$. Additionally, the W12 ice model with $\mu_{\mathrm{UM}}=1 \times 10^{21} \mathrm{Pas}$ and $\mu_{\mathrm{LM}}=1 \times 10^{22}$ (M3) is also used. The last row indicates the average value and uncertainty due to GRACE measurement error and uncertainty in the GIA model.

\begin{tabular}{llrrrr}
\hline Ice model & Rheology & Novaya Zemlya & Svalbard & Franz J. Land & Severnaya Zemlya \\
\hline GLAC1 & M2 & $4.71 \pm 0.42$ & $5.05 \pm 0.49$ & $1.12 \pm 0.19$ & $0.76 \pm 0.10$ \\
GLAC1 & VM5a & $4.94 \pm 0.42$ & $4.96 \pm 0.49$ & $1.10 \pm 0.19$ & $0.63 \pm 0.10$ \\
GLAC2 & M2 & $4.60 \pm 0.42$ & $4.90 \pm 0.49$ & $0.93 \pm 0.19$ & $0.92 \pm 0.10$ \\
GLAC2 & VM5a & $4.57 \pm 0.42$ & $4.85 \pm 0.49$ & $0.85 \pm 0.19$ & $0.67 \pm 0.10$ \\
ICE-5G & M2 & $5.87 \pm 0.42$ & $5.77 \pm 0.49$ & $1.68 \pm 0.19$ & $0.80 \pm 0.10$ \\
ICE-5G & VM5a & $4.54 \pm 0.42$ & $5.16 \pm 0.49$ & $1.03 \pm 0.19$ & $0.70 \pm 0.10$ \\
W12 & M3 & $6.13 \pm 0.42$ & $5.34 \pm 0.49$ & $1.64 \pm 0.19$ & $0.46 \pm 0.10$ \\
- & - & $5.15 \pm 0.58$ & $5.05 \pm 0.79$ & $1.19 \pm 0.38$ & $0.70 \pm 0.18$ \\
\hline
\end{tabular}

seas (Peralta-Ferriz, 2012). The version of the ocean model we use is the ECCOv4-1lc270 compilation. This compilation covers the period 2001-2015, which means the GRACE time series that we use in the Barents Sea is limited to this period. We obtain gravity rates in the central Barents Sea using the UTCSR GRACE solution corrected with both the OMCT and the ECCO ocean models. The differences between these two solutions are used as an indication of the uncertainty in nontidal ocean changes $\left(\sigma_{\text {ocean }}\right)$.

We estimate the total error in the gravity trends by assuming that the different error sources are uncorrelated as follows:

$\sigma=\sqrt{\sigma_{\text {ice }}^{2}+\sigma_{\text {GRACE }}^{2}+\sigma_{\text {ocean }}^{2}+\sigma_{\text {hydrology }}^{2}}$.

The assumption that errors are uncorrelated requires further discussion. GRACE data are assimilated in the ECCO ocean model. However, GRACE is only one of the 40 data sets used in the inversion process, and the final product does not fit GRACE data well (Yu et al., 2018). Therefore there will be only a weak correlation with the GRACE data used in our estimation. Correlation between land surface hydrology models and present-day ice melt is not expected, because hydrology models have little skill in predicting trends and do not model areas of permanent snow. Finally, ice loss change errors $\left(\sigma_{\text {ice }}\right)$ arise due to uncertainty in the GIA model and GRACE measurement error; we cannot rule out that the second error component might be correlated with $\sigma_{\mathrm{GRACE}}$.

For the Barents Sea we consider the four terms, while for Fennoscandia we only consider GRACE measurement errors, as the ice loss changes in the Russian Arctic archipelago and ocean-bottom pressure changes have a very small effect on the gravity trends recovered in Fennoscandia, and Greenland's mass loss signal is well known from altimetry measurements.

\subsection{GIA Modeling}

We compare GRACE-derived gravity rates with those predicted by GIA models. To compute the gravity trends the sea level equation is solved, using the pseudo-spectral approach presented in Mitrovica and Peltier (1991). We use the same code as Barletta and Bordoni (2013). To be able to run calculations for many different Earth parameters and ice models we assume that solid Earth properties only vary radially, which allows us to compute GIA response for different regions separately with different viscosity profiles but neglects effects of viscosity changes in surrounding regions. While this approach has been used in other GIA studies (Lambeck et al., 1998; Steffen et al., 2014), it has been suggested that far-field viscosity variations are relevant in Fennoscandia (Whitehouse et al., 2006).

We neglect the loading effect due to sediment transport during deglaciation, as the effect is small and well below that of the unknown ice thickness $\left(0.01\right.$ to $0.05 \mu \mathrm{Gal} \mathrm{yr}^{-1}$ in Fennoscandia and below $0.014 \mu \mathrm{Galyr}^{-1}$ in the Barents Sea, as shown in van der Wal and Ijpelaar, 2017). To study the effect of the ice deglaciation history on the present gravity rates we start by using a reference Earth model based on the averaged VM2 model, which is similar to the VM5a model (Peltier, 2004; Argus et al., 2014). The model consists of a $90 \mathrm{~km}$ lithosphere, a $570 \mathrm{~km}$ upper mantle with a viscosity of $0.5 \times 10^{21} \mathrm{Pas}$ and a $2216 \mathrm{~km}$ lower mantle with an average viscosity of $2.6 \times 10^{21} \mathrm{Pas}$. The elastic properties of the Earth are based on the PREM model (Dziewonski and Anderson, 1981). To investigate the effect of the Earth's rheology, we vary the upper mantle viscosity between 0.1 and $1.6 \times 10^{21} \mathrm{Pas}$ and the lithospheric thickness between 40 and $180 \mathrm{~km}$ (Table 2). We do not change the lower mantle as its viscosity cannot be constrained uniquely from data in Fennoscandia (Steffen and Kaufmann, 2005). However, gravity rates are influenced by the lower mantle viscosity, 
Table 2. Solid Earth rheological parameters for this study: lithosphere thickness $\left(h_{1}\right)$, upper mantle viscosity $\nu_{\mathrm{UM}}$ and lower mantle viscosity $\nu_{\mathrm{LM}}$.

\begin{tabular}{lrr}
\hline Parameter & Reference model & Range \\
\hline$h_{1}(\mathrm{~km})$ & 90 & $40-180$ \\
$\nu_{\mathrm{UM}}\left(10^{21} \mathrm{Pas}\right)$ & 0.5 & $0.1-1.6$ \\
$\nu_{\mathrm{LM}}\left(10^{21} \mathrm{Pas}\right)$ & 2.6 & 2.6 \\
\hline
\end{tabular}

which is discussed in the comparison with other GIA studies for the region.

We use an ensemble of ice histories that reflects the uncertainty in the deglaciation history of the European Ice Sheet Complex (EISC), the amount of ice in the SBKIS and the Scandinavian Ice Sheet (SIS) for the different ice deglaciation scenarios shown in Fig. 2 . The ice sheet models that we use can be divided into two main categories: (1) empirical ice sheet models based on GIA observables and empirically determined ice extents and (2) those based on numerical icesheet modeling forced under different paleo-climate scenarios and tuned to fit different constrains. A fundamental difference between these two kinds of models is that GIA-based paleo-ice sheet models are explicitly associated with a specific Earth model. The first set of models is represented by the ICE-5G and ICE-6G models (Peltier, 2004; Peltier et al., 2015; Argus et al., 2014). Both models start the ice build-up at $122 \mathrm{ka}$. The second set consists of three models obtained using the Glacial System Model (GSM) for northern Europe (Tarasov et al., 2012), the University of Troms $\varnothing$ Ice Sheet Model (UiT ISM) (Patton et al., 2016, 2017) and the S04 ice sheet model (Siegert and Dowdeswell, 2004), which are further described below. Figure 2 shows the ice model with the largest LGM ice volume (ICE-6G) and the model with the smallest ice volume (S04).

The three ice sheet models obtained using the GSM model are a subset of a bigger ensemble used in Root et al. (2015a), which showed good agreement with GRACE observations. The ensemble was obtained using a Bayesian calibration of GSM runs with RSL curves, present-day ground velocities and ice deglaciation margins from the DATED-1 project (Hughes et al., 2016). The VM5a rheology model was employed as reference during the calibration process; however, errors introduced by the rheology model were accounted for during the calibration process, which implies that this model is not as strongly biased by a single viscosity profile as the ICE-5G and ICE-6G models. The three selected models consist of a late deglaciation model, labeled nn 45283 in Root et al. (2015a) and two early deglaciation models, nn56536 and nn56597, with different maximum ice volumes. The build-up phase is faster than for the ICE-5G and ICE-6G models; build-up starts $28 \mathrm{ka}$. The models will be labeled T1 (nn45283), T2 (nn56536) and T3 (nn56597) to simplify the notation.
The University of Tromsø Ice Sheet Model is based on a 3D thermomechanical ice model which uses an approximation of the Stokes equations forced by climatic and eustatic sea level perturbations to simulate the evolution of the EISC. The model is constrained using different geophysical and geological data sets including geomorphological flow sets, moraine and grounding zone wedge positions, and isostasy patterns and is consistent with the DATED-1 ice sheet margins. Isostatic loading is implemented using the elastic lithosphere/relaxed asthenosphere model of Le Meur and Huybrechts (1996). The model has no ice in the region before $37 \mathrm{ka}$.

Finally, we consider an ice sheet model which gives a lower bound for the mass present in the Barents Sea during the LGM, the S04 model (Siegert and Dowdeswell, 2004). The model is based on the continuity flow equations coupled with a model of water, basal sediment deformation and transportation. The model is forced with eustatic sea level curves of the last $30 \mathrm{ka}$, paleo-air temperatures and precipitation and assumes an ice-free scenario before $32 \mathrm{ka}$. Bedrock topography is adjusted for isostasy using the method of Oerlemans and van der Veen (1984).

The only global ice sheet models are the ICE-5G and ICE-6G; for the other ice sheet models we use the ICE-6G ice model outside the EISC. We include the build-up and deglaciation phase of the last glacial cycle. All ice sheet models are sampled in a grid with a spatial resolution corresponding to a $128^{\circ}$ Gaussian grid, and the output of the model is truncated at degree 60 and processed using the same filters used to process the GRACE data.

\subsection{Model performance assessment}

We assess the fit of the modeled and estimated gravity rates for different combinations of ice deglaciation history and rheology. As GRACE's resolution is of the same order of magnitude as the extension of the SBKIS we cannot resolve the differences in the shape of the ice sheet in the data. Thus we assess the model fit only by comparing the maximum modeled $\left(m_{i}\right)$ and estimated $\left(e_{i}\right)$ gravity rate in the central Barents Sea and Fennoscandia and normalize this difference using the observation error $\left(\sigma_{i}\right)$. In order to make the results as independent of the filter parameters as possible, we compute an average misfit using different filter configurations as follows:

$\chi^{2}=\frac{1}{N} \sum_{i=1}^{N}\left(\frac{e_{i}-m_{i}}{\sigma_{i}}\right)^{2}$,

where $N$ is the number of filter settings. The low-pass filter is varied between 200 and $300 \mathrm{~km}$ half width in $20 \mathrm{~km}$ intervals. Additionally, in the Barents Sea the high-pass filter is varied between the 500 and $700 \mathrm{~km}$ half width in $100 \mathrm{~km}$ intervals. We cannot formally define a confidence region as GRACE's observations, which are processed with different 
filter configurations, do not form a set uncorrelated observations. Instead, we define a subset of best-fitting models as those that differ less than $2 \sigma$ from the observations, indicating that, given the measurement noise, any of these models could be the best-fitting model for a different realization of the observations. In the following we will refer to the lowest upper mantle viscosity of this set as lower bound.

\section{Results}

\subsection{GRACE GIA signal in Fennoscandia and the Barents Sea}

We use the methods presented in Sect. 2 to obtain the gravity rates over Fennoscandia and the Barents Sea. A clear positive anomaly is evident both in Fennoscandia and the central Barents Sea where the main domes of the Scandinavian Ice Sheet and Svalbard-Barents-Kara Ice Sheet were presumably located (Fig. 1). The melting of ice in Svalbard and the islands of the Russian Arctic archipelago is also evident as a negative gravity trend. After removing the mass loss signal as explained in Sect. 2, we observe that most of the signal of Novaya Zemlya, Svalbard and Franz Josef Land is indeed removed (Fig. 1). However, there is still a negative gravity rate left over Severnaya Zemlya, indicating that our ice loss changes might be underestimated for this island. We consider the remaining part of the signal to be entirely due to GIA and call it the estimated GIA signal. We do not observe a clear positive signal in the Kara Sea, which indicates that if it was glaciated during the LGM, the amount of ice present there was much smaller than that located in the Barents Sea. This fact advocates against the larger ice sheets in Denton and Hughes (1981); Grosswald (1998); Grosswald and Hughes (2002) and further confirms the results of the DATED-1 (Hughes et al., 2016) and QUEEN projects (Svendsen et al., 2004).

We obtain the maximum gravity rate in the Barents Sea for different filter configurations using the OMCT and ECCO ocean models. Figure 3 shows the maximum gravity rates for a $600 \mathrm{~km}$ high-pass filter and different low-pass filter half widths. As expected, we observe that the maximum gravity signal reduces with increasing filter half width and so does the error. The gravity rates recovered using the ECCO ocean model are systematically higher that those obtained with the OMCT model. We show a breakdown of the error (Fig. 4) for different low-pass filter half widths. We observe that the hydrology signal leaking into the Barents Sea is very small and the error budget is dominated by the uncertainty in presentday ice changes, the GRACE measurement error and the nontidal ocean signal. Moreover, we observe that while the other error sources decrease with increasing filter half width, the ocean error does not. This implies that it has a wavelength similar to that of the GIA signal we want to resolve.

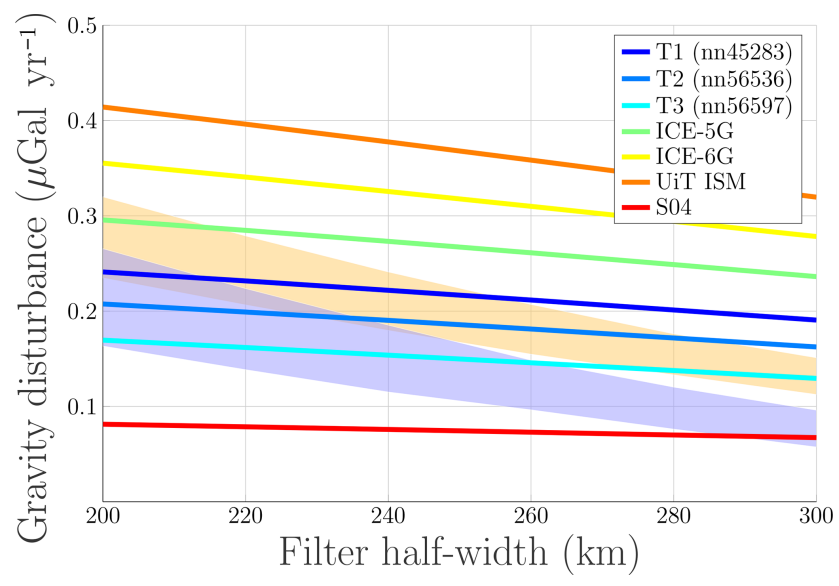

Figure 3. Maximum gravity rate in $\mu \mathrm{Gal} \mathrm{yr}^{-1}$ recovered in the central Barents Sea using GRACE, after removing the ocean signal with the OMCT ocean model (blue) or ECCO ocean model (orange) for different low-pass filter half widths and a $600 \mathrm{~km}$ half width highpass filter. The GIA signal for different ice deglaciation histories with the reference Earth model is also shown.

\subsection{Implications for viscosity and ice sheet chronology}

We perform three experiments. In the first experiment we only study the effect of the ice history on the model misfit. We use the reference Earth model (see Table 2) and compare the fit of the predicted gravity rates for different ice deglaciation models with the GRACE-derived gravity rate. In the second experiment, we change the Earth rheological parameters to obtain the subset of ice deglaciation histories and Earth rheological parameters that best fit the GRACE observations. Thirdly, we repeat the second experiment for Fennoscandia and compare the optimal solid Earth parameters for both regions to detect possible variations in rheological parameters.

Figure 3 compares the maximum present-day estimated gravity rates in the Barents Sea with those given by the different ice sheet models. It must be noted that the maximum gravity rates produced by each ice history are related to not only the maximum ice volume attained during LGM, but also its geographical distribution and the onset of the deglaciation process. As an example, we find that while the T2 model has more ice in the Barents Sea than the T1 model, it results in lower gravity rates. This is because deglaciation starts earlier in the T2 model than in the T1 model, when the sensitivity of the present gravity rates to mass changes is higher as shown in Fig. 5. Similarly, the highest gravity rates are associated with the UiT ISM even though it has less ice than the ICE-5G and ICE-6G models. This is because the UiT ice sheet model has more ice in the central Barents Sea during the last phase of deglaciation. In fact, the model includes an ice bridge between Svalbard, Franz Josef Land and Novaya Zemlya with ice thickness as large as $2000 \mathrm{~m}$ at $14.5 \mathrm{ka}$ which does not disappear until $12 \mathrm{ka}$. This is not present in either the ICE$6 \mathrm{G}$ or the ICE-5G models. 


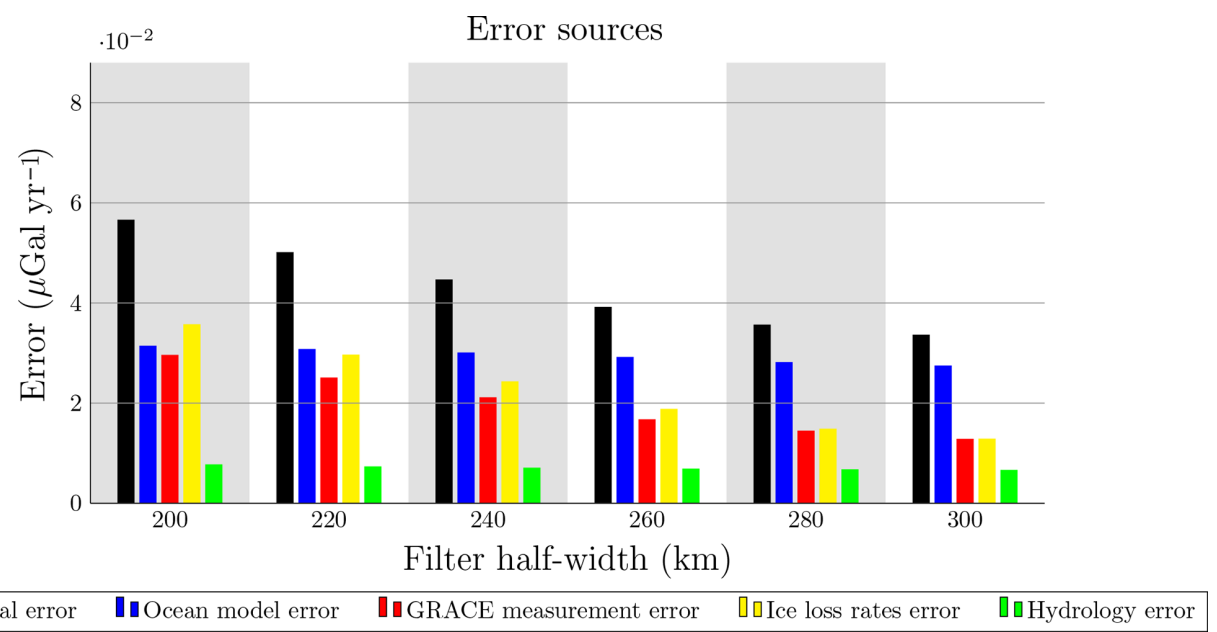

Figure 4. Error in $\mu \mathrm{Gal} \mathrm{yr}^{-1}$ in the maximum gravity rate in the central Barents Sea from different sources. The magnitude of the error is given for different low-pass filter half widths and a high-pass filter half width of $600 \mathrm{~km}$.

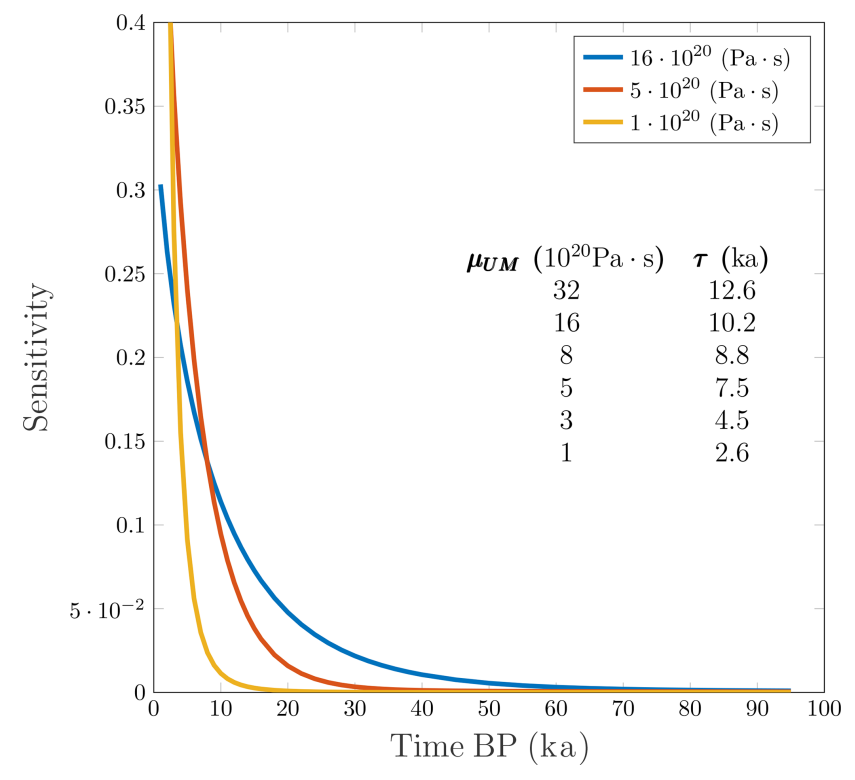

Figure 5. Present gravity disturbance rate induced by a uniform mass change in the Barents Sea at a given epoch for three different upper mantle viscosity. The results have been normalized using the maximum gravity disturbance rate obtained with $\mu_{\mathrm{UM}}=$ $1 \times 10^{20} \mathrm{~Pa}$ s. Inset: relaxation times for different upper mantle viscosity.

When we compare the modeled and estimated gravity rates we find that, for the reference Earth model, the T1, T2 and T3 ice sheet models are the closest to observations. The S04 ice sheet model performs worse; the model does not have enough ice in the region. This result is in accordance with Auriac et al. (2016), which found poor agreement between the S04 model and RSL curves. The more massive ICE-5G, ICE-6G and UiT models result in gravity rates that are too high. However, the discrepancy between these models and
GRACE-derived estimations is reduced if we use the ECCO ocean model instead of the OMCT. Furthermore, GRACE data can be reconciled with the UiT ISM if the maximum volume of mass in the model is reduced by around $1 \mathrm{~m}$ of equivalent sea level rise or if deglaciation started $1 \mathrm{kyr}$ earlier.

Next, we study the effects of changing the solid Earth rheology in the Barents Sea. Figures 6a, c, e and g and 7a, c and e show the misfit of the different ice sheet models to the estimated maximum gravity rates in the Barents Sea for different rheology models. We see that there is a large subset of Earth rheological parameters for which the modeled gravity rate is within $2 \sigma$ of GRACE's estimated gravity rate.

The T1, T2 and T3 ice sheet models present a good fit to the observations for a large subset of Earth models including the reference Earth model $\left(\nu=5 \times 10^{20} \mathrm{Pas} ; h=90 \mathrm{~km}\right)$. For the less massive S04 model the $2 \sigma$ interval extends from $v=8 \times 10^{20}$ to $v=1.6 \times 10^{21} \mathrm{~Pa}$. In contrast, for the more massive ice sheets (ICE-5G, ICE-6G and UiT ISM) the subset of Earth models which present a good fit to the Barents Sea observations is smaller and does not contain the reference Earth model. These models, however, fit the observations for either a less viscous upper mantle or a thicker lithosphere when upper mantle viscosity is fixed. If a less viscous upper mantle viscosity is used, the relaxation time of the solid Earth is decreased, and the sensitivity to mass changes that occurred during the LGM decreases (see Fig. 5). On the other hand, a thicker lithosphere acts as a low-pass filter, which smooths the gravity signal, reducing its maximum value.

Our results for the UiT ISM are consistent with those obtained by Patton et al. (2017), which inferred an upper mantle viscosity of $2 \times 10^{20} \mathrm{Pas}$ based on RSL data. The lower bound obtained with the other ice models is similar as models with a low viscosity have little sensitivity to mass changes during the early deglaciation phase, where differ- 


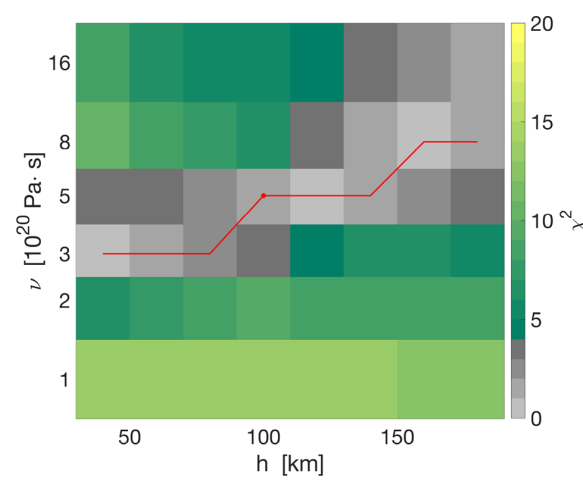

(a) T1 Barents Sea

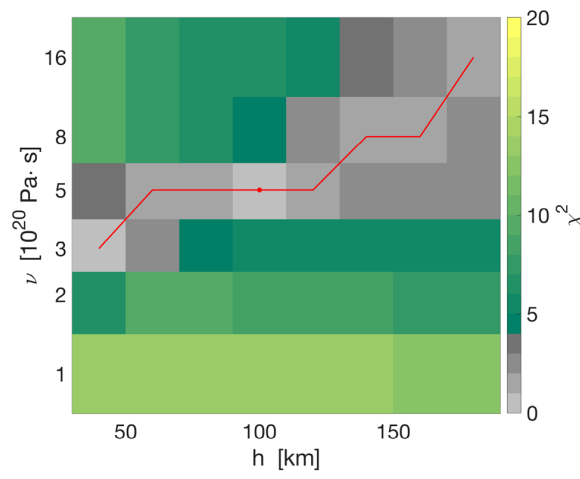

(c) T2 Barents Sea

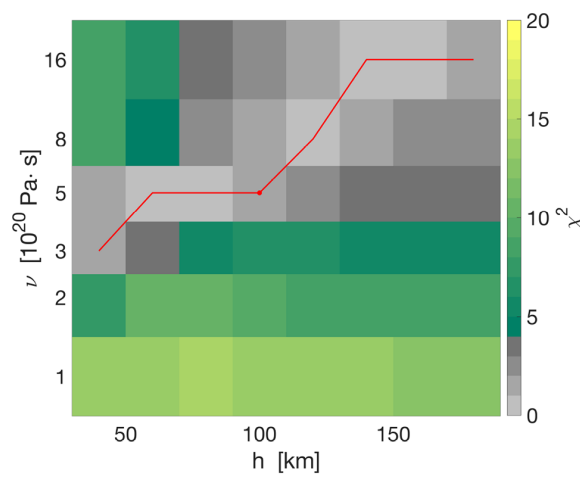

(e) T3 Barents Sea

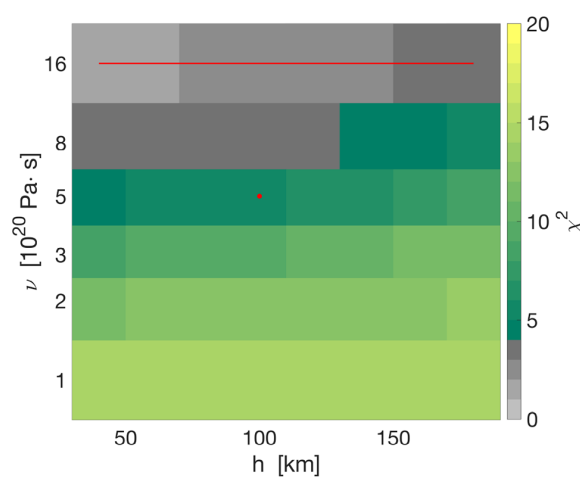

(g) S04 Barents Sea

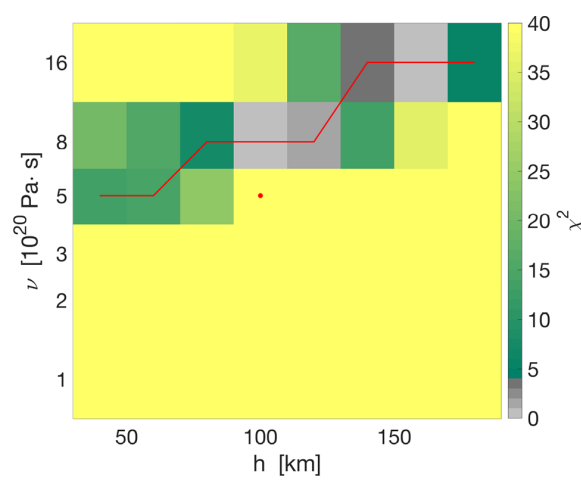

(b) T1 Fennoscandia

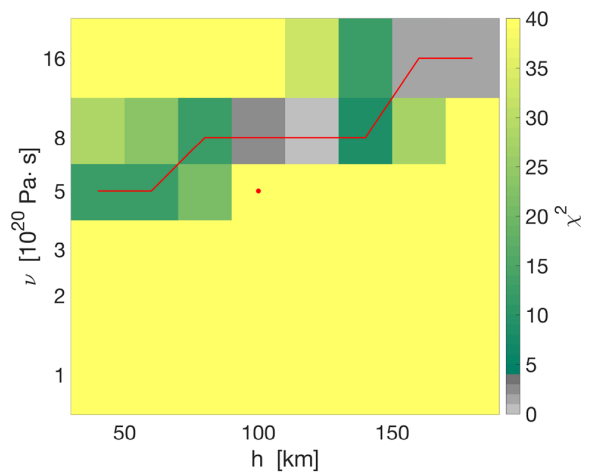

(d) T2 Fennoscandia

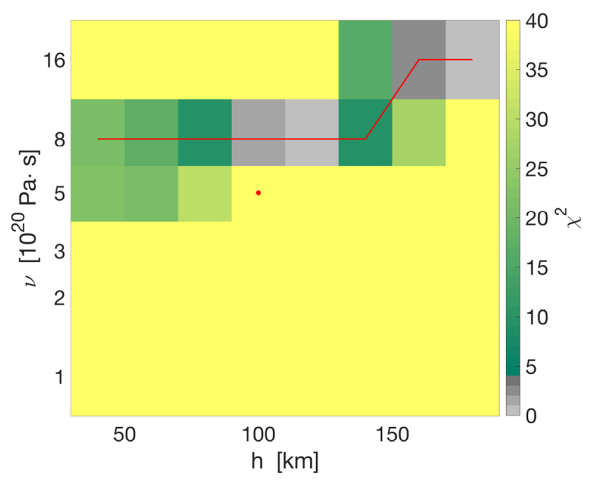

(f) T3 Fennoscandia

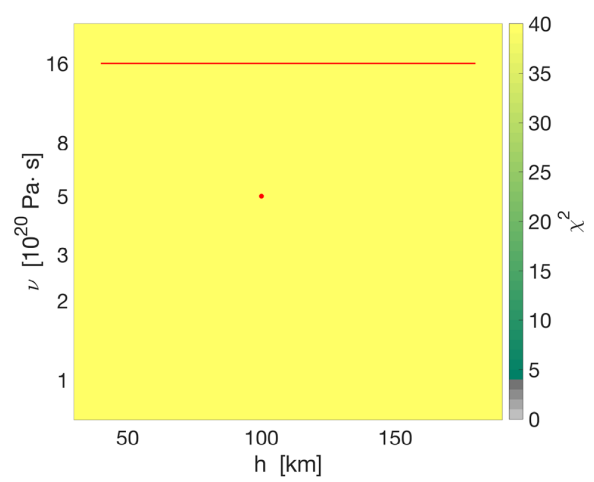

(h) S04 Fennoscandia

Figure 6. Misfit of the T1, T2, T3 and S04 ice deglaciation chronologies to GRACE observations for different values of upper mantle viscosity $(v)$ and lithospheric thickness $(h)$ in $(\mathbf{a}, \mathbf{c}, \mathbf{e}, \mathbf{g})$ the Barents Sea and $(\mathbf{b}, \mathbf{d}, \mathbf{f}, \mathbf{h})$ Fennoscandia. The fit is given in terms of the $\chi^{2}$ The circle indicates the reference model, and the red line shows the best-fitting model for each lithospheric thickness. 


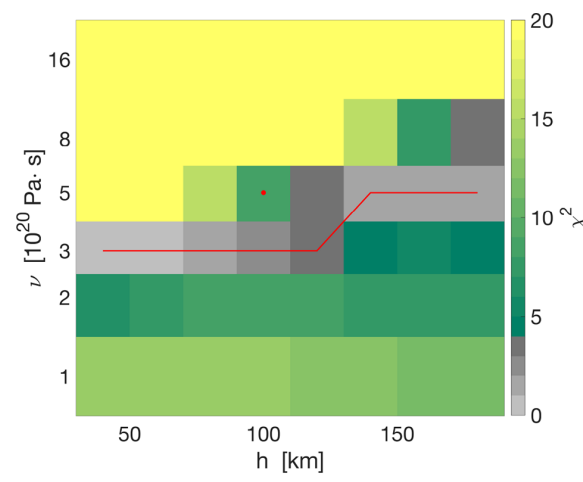

(a) ICE-6G Barents Sea

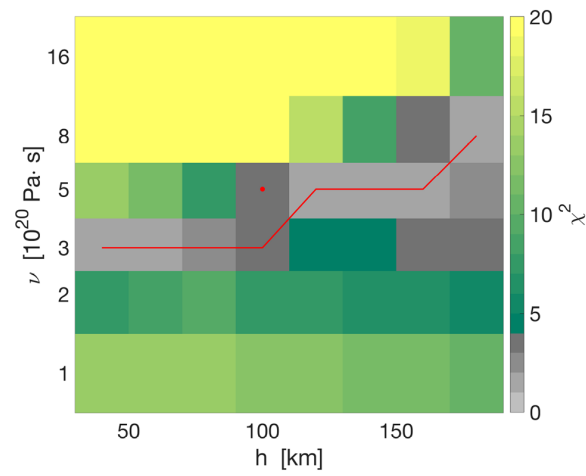

(c) ICE-5G Barents Sea

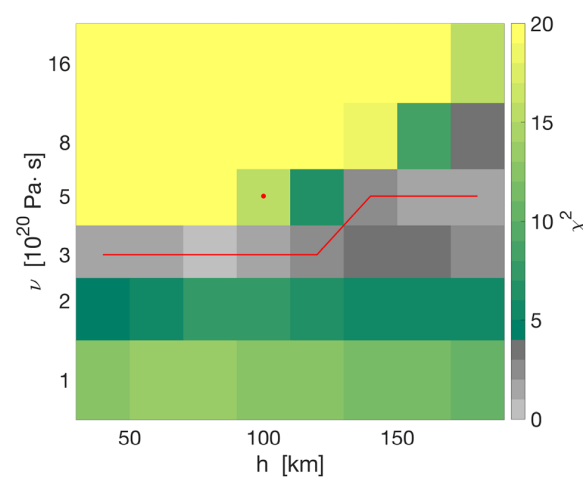

(e) UiT Barents Sea

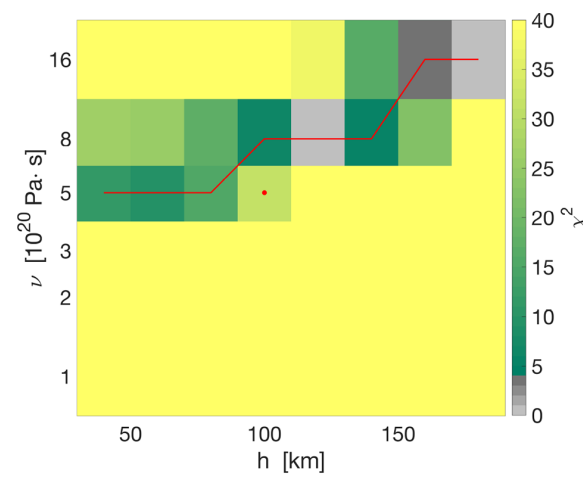

(b) ICE-6G Fennoscandia

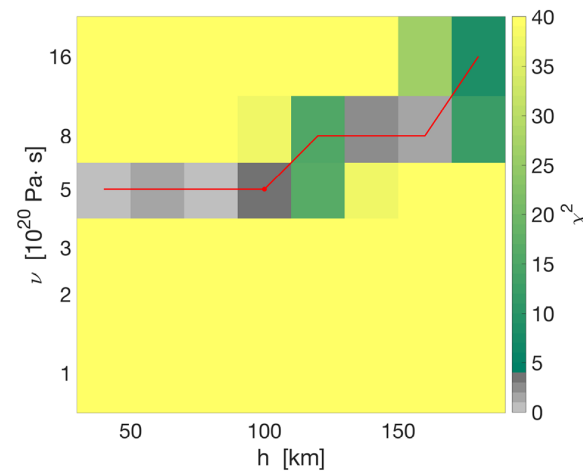

(d) ICE-5G Fennoscandia

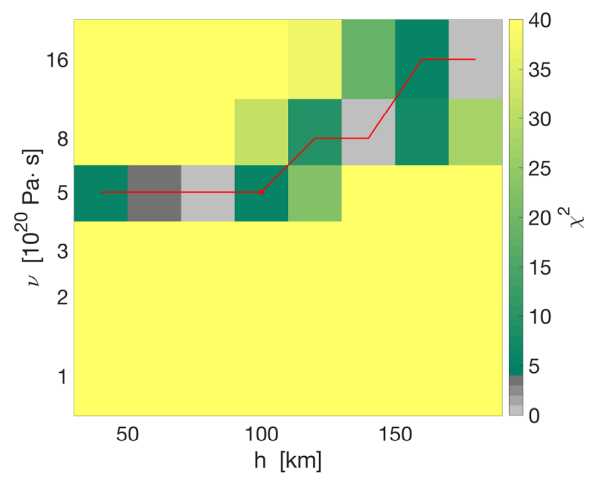

(f) UiT Fennoscandia

Figure 7. Same as Fig. 6 but for the ICE-6G, ICE-5G and UiT ice sheet models.

ences between ice models are more manifest (Fig. 2). Overall, for a lower mantle viscosity of $2.6 \times 10^{21} \mathrm{~Pa}$, we obtain a lower bound for the upper mantle viscosity of $3 \times 10^{20} \mathrm{Pas}$, which agrees with the range of possible upper mantle viscosity found in Auriac et al. (2016) using RSL curves and GPS uplift measurements. We refrain from drawing conclusions on the preferred lithosphere thickness from the misfit plots because the lithosphere has a large influence on the shape of the gravity rate pattern, which was not used as constraint here. A higher lower mantle viscosity can result in a lower upper mantle viscosity that still provides a good fit, as shown in Steffen et al. (2010), Root et al. (2015b).
We follow the same procedure for Fennoscandia to obtain the subset of Earth rheological parameters and ice sheet deglaciation histories with an acceptable agreement with the GRACE observations (see Figs. 6b, d, $f$ and $h$ and $7 b$, d and f). It must be noted that the values of the $\chi^{2}$ are higher for Fennoscandia than the Barents Sea, and thus the subset of models within the $2 \sigma$ contour is smaller. The reason is 2 -fold: the observation error is smaller as compared with the Barents Sea, where uncertainty from mass changes in the glaciers of the surrounding islands and non-tidal ocean changes increase the error bars; and the GIA signal is higher in Fennoscandia than in the Barents Sea (see Fig. 1). Nevertheless we can compare the best-fitting models for both regions. 
We observe that, contrary to what we got for the Barents Sea, the combination of the ice sheet models ICE-5G and UiT with the reference lithospheric thickness and upper mantle viscosity have a good fit (Figs. 6 and 7). As already mentioned, the ICE-5G and ICE-6G models have been constrained using GIA observations, which are abundant in Fennoscandia. As we are using these models with an Earth rheology similar to its reference rheology it is not surprising that the ICE-5G model presents a good fit in this region; however the ICE-6G model performs better with a more viscous mantle due to its lower ice volume. The T1-3 models do not fit the estimated GIA signal with the reference Earth model and require a more viscous mantle. The early deglaciation and small LGM ice volume of the S04 model results in low gravity disturbance rates that do not fit the GRACE estimated gravity disturbance rates for the set of rheology parameters considered in this study. For Fennoscandia we find a lower bound for the upper mantle viscosity of $5 \times 10^{20} \mathrm{Pas}$, which is consistent with current estimates (Simon et al., 2018).

We can infer lateral rheology changes by comparing the optimal Earth rheological parameters obtained for both regions. For each ice deglaciation chronology, we compare the two $2 \sigma$ intervals as well as the best-fitting upper-mantle viscosity obtained for each lithospheric thickness. We observe that for the UiT, ICE-5G and ICE-6G models both the $2 \sigma$ intervals and the best-fitting models systematically prefer a less viscous upper mantle in the Barents Sea as compared with Fennoscandia. This is also the case for the T1,T2 and T3 models when the best-fitting models are compared, although there is an overlap of models of high upper mantle viscosity and thick lithospheres with a good fit in both regions. This systematic difference is likely evidence of lateral variation in Earth rheology.

\subsection{Lateral viscosity variation}

To strengthen the conclusion of viscosity differences between the two regions, we derive viscosity estimates in an independent way, based on seismic velocity anomalies and experimentally derived flow laws. The absolute viscosity values obtained in this way contain large uncertainty, but the relative difference resulting from the seismic models should represent real change in temperature or composition. Therefore we focus on the ratio between the viscosities beneath Fennoscandia and the Barents Sea and check whether it agrees with the outcome of the GIA model misfit.

To take uncertainty in seismic velocity anomalies into account we use two global seismic tomography models: S40RTS (Ritsema et al., 2011) and Schaeffer and Lebedev (2013) (labeled SL), which has higher spatial resolution but reduced sensitivity with depth. For both, the reference model is adjusted to account for a jump in the seismic velocity anomaly in PREM (Dziewonski and Anderson, 1981) and AK135 (Kennett et al., 1995) below $200 \mathrm{~km}$. Shear wave velocities are converted to temperature using re- lations from geochemistry (Goes et al., 2000; Cammarano et al., 2003) for primitive mantle composition and accounting for anelasticity (anelastic correction model Q4 from Cammarano et al., 2003). Differences in composition between the Barents Sea and Scandinavia could play a role but is unlikely to reverse the temperature contrast, due to the first order effect of temperature on seismic velocities in the upper mantle (Goes et al., 2000). To compute viscosity we follow the procedure in Wal et al. (2013) and insert temperatures in the olivine flow laws of Hirth and Kohlstedt (2013). The flow laws for diffusion and dislocation are added, which means the viscosity depends on grain size and stress. Stress is taken from a 3D GIA model which uses the ICE-5G ice load. Background stresses due to mantle convection are neglected as recent work suggest little interaction between GIA and mantle convection (Huang, 2018). Grain size is chosen to be 4 or $10 \mathrm{~mm}$. The $4 \mathrm{~mm}$ size gave best overall fit to GIA data, and $10 \mathrm{~mm}$ grain size resulted in the best fit with the observed maximum uplift rate (Wal et al., 2013).

To be able to compare against viscosity for the upper mantle in the previous section we use viscosity averaged between 225 and $325 \mathrm{~km}$. This depth is a trade-off; shallower layers have lower temperature and small viscous deformation during the glacial cycle, while for deeper layers the seismic models are less accurate. The depth range is also close to the depth to which the gravity rate in Fennoscandia is most sensitive; see the sensitivity kernels in van der Wal et al. (2011). The viscosity maps are plotted in Fig. 8. In principle all viscosity values around the ice load play a role in the GIA process, but the highest sensitivity is to values directly underneath the ice load (Paulson et al., 2005; Wu, 2006). We compute the average of viscosities for the locations where LGM ice heights are above $1500 \mathrm{~m}$, which covers most of the land mass of Scandinavia and most of the Barents Sea (see dashed brown contour). Viscosity is computed separately for the region below $71^{\circ}$ latitude for Fennoscandia and above for the Barents Sea. We find that the average viscosity below Fennoscandia is a factor of 2.3 to 2.4 times higher than that in the Barents Sea. This agrees well with the change in best fit upper mantle viscosity that can be seen in the misfit Figs. 6 and 7. There could still be an effect of 3D structure that is not captured by modeling both regions with 1D models, such as lateral variations within Fennoscandia (Steffen et al., 2014) or the influence of viscosity from outside each region.

\section{Conclusions and discussion}

In this study, we analyze GRACE data in the Barents Sea to constrain the Earth rheology in the region. We compare the fit of different GIA models in Fennoscandia with that for the Barents Sea to find if there is a difference in viscosity between the two regions. We investigate several deglaciation chronologies of the SBKIS, some of which are not explicitly tied to a viscosity model. We use GRACE data for the period 

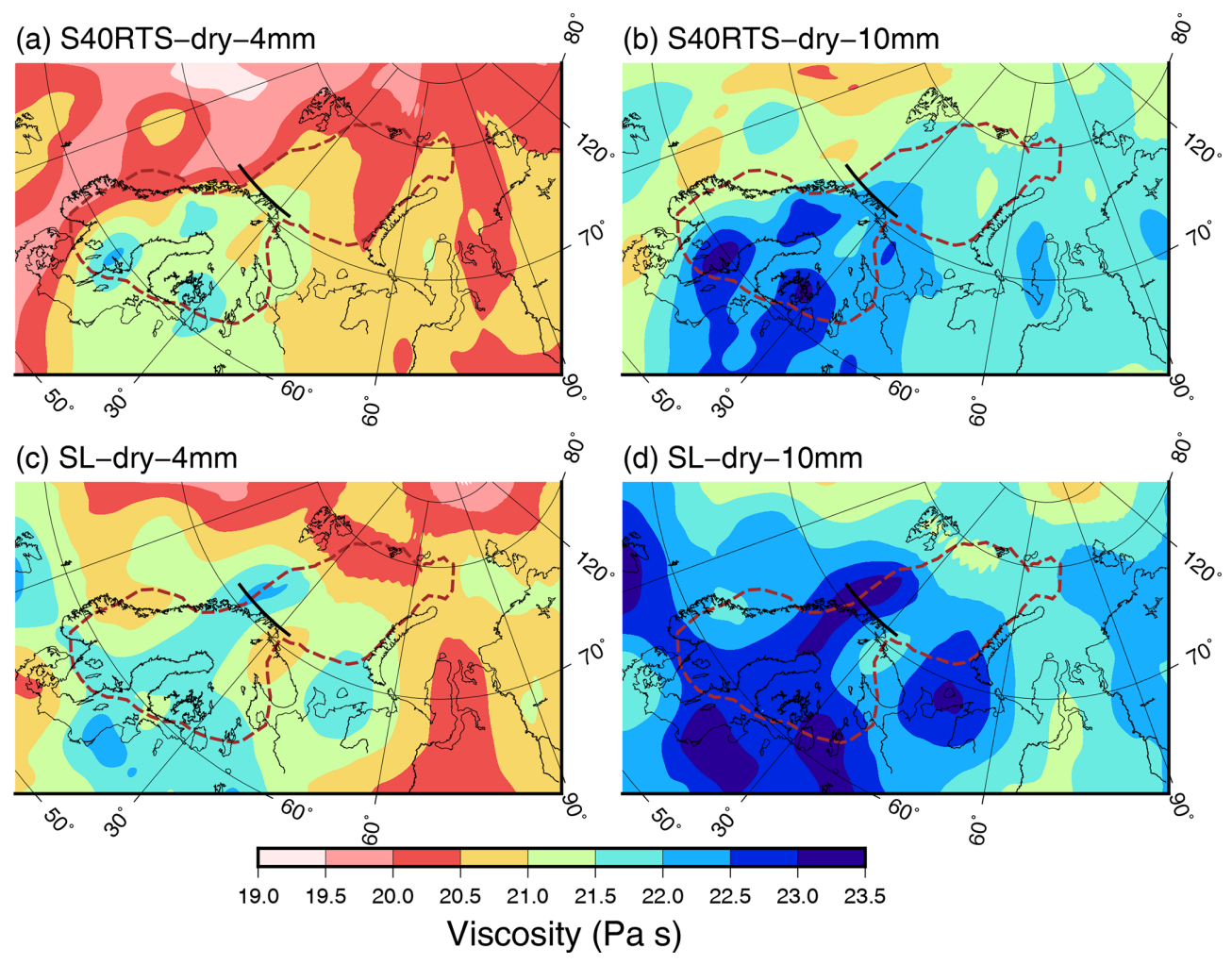

Figure 8. Viscosity between depths of 225 and $325 \mathrm{~km}$ derived from seismic models (a, b) S40RTS (Ritsema et al., 2011) and (c, d) Schaeffer and Lebedev (2013) and for different flow law parameters: (a, c) $4 \mathrm{~mm}$ grain size and (b, d) $10 \mathrm{~mm}$ grain size. The brown line denotes the $1500 \mathrm{~m}$ ice height contour at LGM in the ICE-5G model; the black line denotes $71^{\circ}$ latitude, which separates the areas used for computing the viscosity for Fennoscandia and the Barents Sea.

2003-2015 and process the data to reveal the GIA signal. The ice loss signal from the Svalbard and the Russian Arctic archipelago is removed using mass change values obtained from GRACE using the mascon method. We observe a positive gravity anomaly in the Barents Sea but no significant anomaly in the Kara Sea, which shows that the ice cover at LGM was considerably thinner there than in the Barents Sea, in agreement with recent studies.

The Barents Sea GIA signal is in a region now covered by sea; therefore, the gravity trends might be affected by nontidal oceanic mass changes. We correct GRACE gravity rates in the Barents Sea using either of the two ocean models, OMCT and ECCO, and find higher gravity rates using the ECCO model. The difference in the ocean signal according to the two models is large in the Barents Sea. This uncertainty has not been considered in previous studies of the GIA signal in the region (e.g., Root et al., 2015a; Simon et al., 2018; Kachuck and Cathles, 2018), and thus the errors bars in those studies were underestimated. This result has also implications for GRACE studies of non-oceanic mass changes, such as post seismic deformations, in ocean areas (e.g., Han and Simons, 2008; Wang et al., 2012), which possibly have higher uncertainty than previously thought due to errors in the ocean model.
We compare the GRACE-derived gravity rates with modeled ones to infer geophysical constraints for the Earth rheology and ice sheet chronology in the Barents Sea region. For a three-layer average of the VM2 viscosity profile (Peltier, 2004) we find, as Root et al. (2015a), that thick ice sheet models (ICE-5G, ICE-6G and UiT) do not fit GRACE observations, while the less massive ice models (T1,T2 and $\mathrm{T} 3$ ) do. Upper mantle viscosity and lithospheric thickness were varied for each ice sheet chronology between $0.1 \times 10^{21}$ and $1.6 \times 10^{21} \mathrm{Pas}$ and 40 and $180 \mathrm{~km}$. We find that the ICE-5G, ICE-6G and UiT ice sheet models can be reconciled with GRACE observations provided the upper mantle viscosity is lower or the lithosphere thicker than in the VM2 model. The same conclusion is reached in Auriac et al. (2016) using GPS uplift measurements and RSL curves instead of gravity data.

The interplay between ice deglaciation chronology and Earth rheology makes it difficult to constrain the ice deglaciation chronology in the Barents Sea (Kachuck and Cathles, 2018). Root et al. (2015a) used GRACE data to conclude that the SBKIS had less ice than previously thought (5-6.3 m of equivalent sea level versus $8.3 \mathrm{~m}$ ). To do so, they used ICE-5G and ICE-6G and showed that they do not obtain the estimated gravity rate when these ice models are combined with their corresponding Earth rheology model. How- 
ever, here we use the UiT ISM, which does not come with an a priori Earth rheology model and contains around $7.5 \mathrm{~m}$ of equivalent sea level rise and show that the model can fit GRACE observations provided the upper mantle viscosity is around $3 \times 10^{20} \mathrm{~Pa}$ if the lithosphere is thinner than $130 \mathrm{~km}$. However, we are able to place a constraint on upper mantle viscosity. From the misfit of all investigated ice chronologies and using a lower mantle viscosity of $2.6 \times 10^{21} \mathrm{~Pa}$ s, we find that best-fitting models have an upper mantle viscosity equal to or higher than $3 \times 10^{20} \mathrm{Pas}$, which agrees with previous constraints derived from RSL and GPS uplift observations Auriac et al. (2016).

We also study the misfit of GRACE observations to the GIA models in Fennoscandia. For a $2.6 \times 10^{21}$ Pas lower mantle viscosity, best-fitting models have an upper mantle viscosity equal to or higher than $5 \times 10^{20} \mathrm{Pas}$, which is consistent with current estimates. Given all of the ice sheet deglaciation chronologies we find that the lower bound for the upper mantle viscosity is a factor of 2 smaller in the Barents Sea (or, alternatively, the lithosphere thickness should be increased there). Unless all of the tested ice deglaciation chronologies are biased in the same direction, this result is evidence of lateral changes in viscosity in between the two regions.

To strengthen the finding of viscosity difference between the two regions, we compare our results with viscosity derived from global velocity anomalies and flow laws for mantle material and find that the average viscosity in the Barents Sea is a factor of 2.4 lower than in Fennoscandia. This agrees very well with the results derived from the misfit of GIA models to GRACE data and strengthens the conclusion that there is a small but significant difference in average upper mantle viscosity between the two regions. This findings have implications for ice sheet models inverted with just one viscosity profile (e.g., ICE-5G, ICE-6G) and advocates in favor of including lateral Earth rheological parameters in GIA models. The constraints on viscosity variations can be also used to calibrate other geodynamic models of the regions.

Code and data availability. Gravity rates for the different ice sheet models and Earth rheology models and GRACE maximum disturbance rates for Fennoscandia and the Barents Sea are provided at https://doi.org/10.4121/uuid:424126e6-b5d3-4ac9-b5cdf495c8ad6939 (Rovira-Navarro et al., 2019). The GIA code used for the simulations is available upon request from Valentina R. Barletta.

Author contributions. All authors contributed to the discussion and commented on the manuscript. MRN and WvdW led the writing of the article. VRB contributed with her GIA code. MRN analyzed GRACE data and ran the GIA simulations. WvdW provided the 3D viscosity maps. All authors contributed to the interpretation of the results.
Competing interests. The authors declare that they have no conflict of interest.

Acknowledgements. The authors would like to thank Lev Tarasov, Henry Patton and Martin J. Siegert for making their ice sheet models available for this study (T1, T2 and T3; UiT ISM and S05 model). The authors also thank Ernst J. O. Schrama for providing mass loss changes in the islands of the Russian Arctic archipelago for this work and Ward Stolk for his contribution to the viscosity maps. The authors also thank Ian Fenty for his assistance and advice on the ECCO ocean model products. Marc Rovira-Navarro would like to thank Fundacio la Caixa for the financial support he received while conducting this research.

Financial support. This research has been partially supported by La Caixa Foundation postgraduate studies program.

Review statement. This paper was edited by Nicolas Gillet and reviewed by two anonymous referees.

\section{References}

Argus, D. F., Peltier, W. R., Drummond, R., and Moore, A. W.: The Antactica component of postglacial rebound model ICE-6G_C (VM5a) based on GPS positioning, exposure age dating of ice thickness and relative sea level histories, Geophys. J. Int., 198, 537-563, https://doi.org/10.1093/gji/ggu140, 2014.

Auriac, A., Whitehouse, P. L., Bentley, M. J., Patton, H., Lloyd, J. M., and Hubbard, A.: Glacial isostatic adjustment associated with the Barents Sea ice sheet : A modelling inter-comparison, Quaternary Sci. Rev., 147, 122-135, https://doi.org/10.1016/j.quascirev.2016.02.011, 2016.

Barletta, V. and Bordoni, A.: Effect of different implementations of the same ice history in GIA modeling, J. Geodyn., 71, 65-73, https://doi.org/10.1016/j.jog.2013.07.002, 2013.

Barnhoorn, A., van der Wal, W., and Drury, M. R.: Upper mantle viscosity and lithospheric thickness under Iceland, J. Geodyn., 52, 260-270, https://doi.org/10.1016/j.jog.2011.01.002, 2011.

Bettadpur, S.: Gravity Recovery and Climate Experiment Level-2 Gravity Field Product User Handbook, UTCSR, Texas, USA, 2012.

Cammarano, F., Goes, S., Vacher, P., and Giardini, D.: Inferring upper-mantle temperatures from seismic velocities, Phys. Earth Planet. Int., 138, 197-222, https://doi.org/10.1016/S00319201(03)00156-0, 2003.

Cheng, M., Tapley, B. D., and Ries, J. C.: Deceleration in the Earth's oblateness, J. Geophys. Res.-Sol. Ea., 118, 740-747, https://doi.org/10.1002/jgrb.50058, 2013.

de Linage, C., Rivera, L., Hinderer, J., Boy, J.-P., Rogister, Y., Lambotte, S., and Biancale, R.: Separation of coseismic and postseismic gravity changes for the 2004 Sumatra-Andaman earthquake from $4.6 \mathrm{yr}$ of GRACE observations and modelling of the coseismic change by normal-modes summation, Geophys. J. Int., 176, 695-714, https://doi.org/10.1111/j.1365246X.2008.04025.x, 2009. 
Denton, G. and Hughes, T.: The Last Great Ice Sheets, WileyInterscience, New York, 1981.

Dobslaw, H., Flechtner, F., Dahle, C., Dill, R., Esselborn, S., Sasgen, I., and Thomas, M.: Simulating high-frequency atmosphereocean mass variability for dealiasing of satellite gravity observations : AOD1B RL05, J. Geophys. Res., 118, 3704-3711, https://doi.org/10.1002/jgrc.20271, 2013.

Dziewonski, A. M. and Anderson, D. L.: Preliminary reference Earth model, Phys.e Earth Planet. Int., 25, 297-356, https://doi.org/10.1016/0031-9201(81)90046-7, 1981.

Flechtner, F., Dobslaw, H., and Fagiolini, E.: AOD1B Product Description Document for Product Release 05, GFZ German Research Centre for Geosciences, Potsdam, Germany, 2015.

Flechtner, F., Neumayer, K.-H., Dahle, C., Dobslaw, H., Fagiolini, E., Raimondo, J.-C., and Güntner, A.: What Can be Expected from the GRACE-FO Laser Ranging Interferometer for Earth Science Applications?, Surv. Geophys., 37, 453-470, https://doi.org/10.1007/s10712-015-9338-y, 2016.

Forget, G., Campin, J.-M., Heimbach, P., Hill, C. N., Ponte, R. M., and Wunsch, C.: ECCO version 4: an integrated framework for non-linear inverse modeling and global ocean state estimation, Geosci. Model Dev., 8, 3071-3104, https://doi.org/10.5194/gmd8-3071-2015, 2015.

Goes, S., Govers, R., and Vacher, P.: Shallow mantle temperatures under Europe from $\mathrm{P}$ and $\mathrm{S}$ wave tomography, J. Geophys. Res.-Sol. Ea., 105, 11153-11169, https://doi.org/10.1029/1999JB900300, 2000.

Grosswald, M. G.: Late Weichselian ice sheet of Northern Eurasia, Quaternary Res., 13, 1-32, https://doi.org/10.1016/00335894(80)90080-0, 1980.

Grosswald, M. G.: Late-Weichselian ice sheets in Arctic and Pacific Siberia, Quaternary Int., 45, 3-18, https://doi.org/10.1016/S1040-6182(97)00002-5, 1998.

Grosswald, M. G. and Hughes, T. J.: The Russian component of an Arctic Ice Sheet during the Last Glacial Maximum, Quaternary Sci. Rev., 21, 121-146, https://doi.org/10.1016/S02773791(01)00078-6, 2002.

Han, S.-C. and Simons, F. J.: Spatiospectral localization of global geopotential fields from the Gravity Recovery and Climate Experiment (GRACE) reveals the coseismic gravity change owing to the 2004 Sumatra-Andaman earthquake, J. Geophys. Res.-Sol. Ea., 113, B01405, https://doi.org/10.1029/2007JB004927, 2008.

Han, S.-C., Shum, C. K., Jekeli, C., Kuo, C.-Y., Wilson, C., and Seo, K.-W.: Non-isotropic filtering of GRACE temporal gravity for geophysical signal enhancement, Geophys. J. Int., 163, 1825, https://doi.org/10.1111/j.1365-246X.2005.02756.x, 2005.

Hirth, G. and Kohlstedt, D.: Rheology of the upper mantle and the mantle wedge: A view from the experimentalists, in: Inside the Subduction Factory, 2004, edited by: Eiler, J., Geophysical Monograph Series, American Geophysical Union (AGU), Blackwell Publishing Ltd, 83-105, https://doi.org/10.1029/138GM06, 2013.

Huang, P.: Modelling Glacial Isostatic Adjustment with Composite Rheology, PhD thesis, The University of Hong Kong, Pokfulam, Hong Kong, 2018.

Hughes, A. L. C., Gyllencreutz, R., Lohne, O. Y. S., Mangerud, J., and Inge, J.: The last Eurasian ice sheets - a chronological database and time-slice reconstruction, DATED-1, Boreas, 45, 1-45, https://doi.org/10.1111/bor.12142, 2016.
Kachuck, S. B. and Cathles, L. M.: Constraining the geometry and volume of the Barents Sea Ice Sheet, J. Quaternary Sci., 33, 527535, https://doi.org/10.1002/jqs.3031, 2018.

Kaufmann, G. and Wu, P.: Lateral asthenospheric viscosity variations and postglacial rebound: A case study for the Barents Sea, Geophys. Res. Lett., 25, 1963-1966, https://doi.org/10.1029/98GL51505, 1998.

Kennett, B. L. N., Engdahl, E. R., and Buland, R.: Constraints on seismic velocities in the Earth from traveltimes, Geophys. J. Int., 122, 108-124, https://doi.org/10.1111/j.1365246X.1995.tb03540.x, 1995.

Kusche, J., Schmidt, R., Rietbroek, S., and Petrovic, R.: Decorrelated GRACE time-variable gravity solutions by GFZ, and their validation using a hydrological model, J. Geodesy, 83, 903-913, https://doi.org/10.1007/s00190-009-0308-3, 2009.

Lambeck, K.: Constraints on the Late Weichselian ice sheet over the Barents Sea from observations of raised shorelines, Quaternary Sci. Rev., 14, 1-16, https://doi.org/10.1016/02773791(94)00107-M, 1995.

Lambeck, K., Smither, C., and Johnston, P.: Sea-level change, glacial rebound and mantle viscosity for northern Europe, Geophys. J. Int., 134, 102-144, https://doi.org/10.1046/j.1365246x.1998.00541.x, 1998.

Le Meur, E. and Huybrechts, P.: A comparisonon if different ways of dealing with isostasy: Examples from modelling the Antarctic ice sheet during the last grlacial cycle, Ann. Glaciol., 23, 309317, 1996.

Lemoine, J.-M., Bruinsma, S., Loyer, S., Biancale, R., Marty, J.C., Perosanz, F., and Balmino, G.: Temporal gravity field models inferred from GRACE data, Adv. Space Res., 39, 1620-1629, https://doi.org/10.1016/j.asr.2007.03.062, 2007.

Levshin, A. L., Schweitzer, J., Weidle, C., Shapiro, N. M., and Ritzwoller, M. H.: Surface wave tomography of the Barents Sea and surrounding regions, Geophys. J. Int., 170, 441-459, https://doi.org/10.1111/j.1365-246X.2006.03285.x, 2007.

Mangerud, J., Astakhov, V., and Svendsen, J.-I.: The extent of the Barents Kara ice sheet during the Last Glacial Maximum, Quaternary Sci. Rev., 21, 111-119, https://doi.org/10.1016/S02773791(01)00088-9, 2002.

Matsuo, K. and Heki, K.: Current Ice Loss in Small Glacier Systems of the Arctic Islands (Iceland, Svalbard, and the Russian High Arctic) from Satellite Gravimetry, Terrestial Atmospheric Oceanic Science, 24, 657-670, https://doi.org/10.3319/TAO.2013.02.22.01(TibXS), 2013.

Mitrovica, J. X. and Peltier, W. R.: On postglacial geoid subsidence over the equatorial oceans, J. Geophys. Res.-Sol. Ea., 96, 2005320071, https://doi.org/10.1029/91JB01284, 1991.

Moholdt, G., Wouters, B., and Gardner, A. S.: Recent mass changes of glaciers in the Russian High Arctic, Geophys. Res. Let., 39, 110502, https://doi.org/10.1029/2012GL051466, 2012.

Oerlemans, J. and van der Veen, C. J.: Bedrock Adjustment, Springer Netherlands, Dordrecht, 111-123, https://doi.org/10.1007/978-94-009-6325-2_7, 1984.

Patton, H., Hubbard, A., Andreassen, K., Winsborrow, M., and Stroeven, A. P.: The build-up , configuration , and dynamical sensitivity of the Eurasian ice-sheet complex to Late Weichselian climatic and oceanic forcing, Quaternary Sci. Rev., 153, 97-121, https://doi.org/10.1016/j.quascirev.2016.10.009, 2016. 
Patton, H., Hubbard, A., Andreassen, K., Auriac, A., Whitehouse, P. L., Stroeven, A. P., Shackleton, C., Winsborrow, M., Heyman, J., and Hall, A. M.: Deglaciation of the Eurasian ice sheet complex, Quaternary Sci. Rev., 169, 148-172, https://doi.org/10.1016/j.quascirev.2017.05.019, 2017.

Paulson, A., Zhong, S., and Wahr, J.: Modelling post-glacial rebound with lateral viscosity variations, Geophys. J. Int., 163, 357-371, https://doi.org/10.1111/j.1365-246X.2005.02645.x, 2005.

Paulson, A., Zhong, S., and Wahr, J.: Inference of mantle viscosity from GRACE and relative sea level data, Geophys. J. Int., 171, 497-508, https://doi.org/10.1111/j.1365246X.2007.03556.x, 2007.

Peltier, W. R.: Global Glacial Isostasy and the Surface of the Ice-Age Earth: The ICE-5G (VM2) Model and GRACE, Annu. Rev. Earth Sci., 32, 111-149, https://doi.org/10.1146/annurev.earth.32.082503.144359, 2004.

Peltier, W. R., Argus, D. F., and Drummond, R.: Space geodesy constrains ice age terminal deglaciation: The global ICE-6GC (VM5a) model, J. Geophys. Res.-Sol. Ea., 120, 450-487, https://doi.org/10.1002/2014JB011176, 2015.

Peralta-Ferriz, A.: Arctic Ocean Circulation Patterns Revealed by Ocean Bottom Pressure Anomalies, PhD thesis, University of Washington, Seattle, Washington, 2012.

Ritsema, J., Deuss, A., van Heijst, H. J., and Woodhouse, J. H.: S40RTS: a degree-40 shear-velocity model for the mantle from new Rayleigh wave dispersion, teleseismic traveltime and normal-mode splitting function measurements, Geophys. J. Int., 184, 1223-1236, https://doi.org/10.1111/j.1365246X.2010.04884.x, 2011.

Rodell, M., Houser, P., Jambor, U., Gottschalck, K., Meng, C., Aresnault, K., Cosgrove, B., Radakovich, J., Bosilovich, M., Entin, J., Walker, J., Lohmann, D., and Toll, D.: The global land data assimilation dystem, Am. Meteorol. Soc., 85, 381-394, https://doi.org/10.1175/BAMS-85-3-381, 2004.

Root, B. C., Tarasov, L., and van der Wal, W.: GRACE gravity observations constrain Weichselian ice thickness in the Barents Sea, Geophys. Res. Lett., 42, 3313-3320, https://doi.org/10.1002/2015GL063769, 2015a.

Root, B. C., van der Wal, W., Novák, P., Ebbing, J., and Vermeersen, L. L. A.: Glacial isostatic adjustment in the static gravity field of Fennoscandia, J. Geophys. Res.-Sol. Ea., 120, 503-518, 2015 b.

Rovira-Navarro, M., van der Wal, W., Barletta, V. A., Root, B. C., and Sandberg Sørensen, L.: Data underlying the research on GRACE constraints on Earth rheology of the Barents Sea and Fennoscandia, 4TU.Centre for Research Data, https://doi.org/10.4121/uuid:424126e6-b5d3-4ac9b5cd-f495c8ad6939, 2019.

Sakumura, C.: Comparison of Degree 60 and Degree 96 Monthly Solutions. GRACE Technical note 10, Center for Space Research, the University of Texas, 2014.

Sasgen, I., Klemann, V., and Martinec, Z.: Towards the inversion of GRACE gravity fields for present-day icemass changes and glacial-isostatic adjustment in North America and Greenland, J. Geodyn., 59-60, 49-63, https://doi.org/10.1016/j.jog.2012.03.004, 2012.

Schaeffer, A. J. and Lebedev, S.: Global shear speed structure of the upper mantle and transition zone, Geophys. J. Int., 194, 417-449, https://doi.org/10.1093/gji/ggt095, 2013.
Schrama, E. J., Wouters, B., and Rietbroek, R.: A mascon approach to assess ice sheet and glacier mass balances and their uncertainties from GRACE data, J. Geophys. Res., 119, 6048-6066, https://doi.org/10.1002/2013JB010923, 2014.

Siegert, M. J. and Dowdeswell, J. A.: Numerical Modeling of the Late Weichselian Svalbard-Barents Sea Ice Sheet, Quaternary Res., 43, 1-13, https://doi.org/10.1006/qres.1995.1001, 1995.

Siegert, M. J. and Dowdeswell, J. A.: Numerical reconstructions of the Eurasian Ice Sheet and climate during the Late Weichselian, Quaternary Sci. Rev., 23, 1273-1283, https://doi.org/10.1016/j.quascirev.2003.12.010, 2004.

Simon, K. M., Riva, R. E. M., Kleinherenbrink, M., and Frederikse, T.: The glacial isostatic adjustment signal at present day in northern Europe and the British Isles estimated from geodetic observations and geophysical models, Solid Earth, 9, 777-795, https://doi.org/10.5194/se-9-777-2018, 2018.

Sørensen, L. S., Simonsen, S. B., Nielsen, K., Lucas-Picher, P., Spada, G., Adalgeirsdottir, G., Forsberg, R., and Hvidberg, C. S.: Mass balance of the Greenland ice sheet (2003-2008) from ICESat data - the impact of interpolation, sampling and firn density, The Cryosphere, 5, 173-186, https://doi.org/10.5194/tc-5173-2011, 2011.

Steffen, H. and Denker, H.: Glacial isostatic adjustment in Fennoscandia from GRACE data and comparison with geodynamical models, J. Geodyn., 46, 155-164, https://doi.org/10.1016/j.jog.2008.03.002, 2008.

Steffen, H. and Kaufmann, G.: Glacial isostatic adjustment of Scandinavia and northwestern Europe and the radial viscosity structure of the Earth's mantle, Geophys. J. Int., 163, 801-812, https://doi.org/10.1111/j.1365-246X.2005.02740.x, 2005.

Steffen, H. and Wu, P.: Glacial isostatic adjustment in Fennoscandia - A review of data and modeling, J. Geodyn., 52, 169-204, https://doi.org/10.1016/j.jog.2011.03.002, 2011.

Steffen, H., Wu, P., and Wang, H.: Determination of the Earth's structure in Fennoscandia from GRACE and implications for the optimal post-processing of GRACE data, Geophys. J. Int., 182, 1295-1310, https://doi.org/10.1111/j.1365-246X.2010.04718.x, 2010.

Steffen, H., Kaufmann, G., and Lampe, R.: Lithosphere and uppermantle structure of the southern Baltic Sea estimated from modelling relative sea-level data with glacial isostatic adjustment, Solid Earth, 5, 447-459, https://doi.org/10.5194/se-5-447-2014, 2014.

Svendsen, J. I., Astakhov, V. I., Bolshiyanov, D. Y. U., Demidov, I., Dowdeswell, J. A., Gataullin, V., Hjort, C., Hubberten, H. W., Larsen, E., Saarnisto, M., Siegert, M. J., Mangerud, J. A. N., Melles, M., and Mo, P. E. R.: Maximum extent of the Eurasian ice sheets in the Barents and Kara Sea region during the Weichselian, Boreas, 28, 234-252, https://doi.org/10.1111/j.15023885.1999.tb00217.x, 1999.

Svendsen, J. I., Gataullin, V., Mangerud, J., and Polyak, L.: The glacial History of the Barents and Kara Sea Region, in: Quaternary Glaciations- Extent and Chronology, edited by: Ehlers, J. and Gibbard, P., pp. 369-378, Elsevier, Amsterdam, the Netherlands, 2004.

Swenson, S. and Wahr, J.: Post-processing removal of correlated errors in GRACE data, Geophys. Res. Lett., 33, L08402, https://doi.org/10.1029/2005GL025285, 2006. 
Tamisiea, M. E., Mitrovica, J. X., and Davis, J. L.: GRACE Gravity Data Constrain Ancient Ice Geometries and Continental Dynamics over Laurentia, Science, 316, 881-883, https://doi.org/10.1126/science.1137157, 2007.

Tarasov, L., Dyke, A. S., Neal, R. M., and Peltier, W.: A data-calibrated distribution of deglacial chronologies for the North American ice complex from glaciological modeling, Earth Planet. Sc. Lett., 315-316, 30-40, https://doi.org/10.1016/j.epsl.2011.09.010, 2012.

van der Wal, W. and Ijpelaar, T.: The effect of sediment loading in Fennoscandia and the Barents Sea during the last glacial cycle on glacial isostatic adjustment observations, Solid Earth, 8, 955968, https://doi.org/10.5194/se-8-955-2017, 2017.

van der Wal, W., Wu, P., Sideris, M. G., and Shum, C.: Use of GRACE determined secular gravity rates for glacial isostatic adjustment studies in North-America, J. Geodyn., 46, 144-154, https://doi.org/10.1016/j.jog.2008.03.007, 2008.

van der Wal, W., Kurtenbach, E., Kusche, J., and Vermeersen, B.: Radial and tangential gravity rates from GRACE in areas of glacial isostatic adjustment, Geophys. J. Int., 187, 797-812, https://doi.org/10.1111/j.1365-246X.2011.05206.x, 2011.

Wahr, J.: 3.08 - Time Variable Gravity from Satellites, in: Treatise on Geophysics, edited by: Schubert, G., pp. 213-237, Elsevier, Amsterdam, https://doi.org/10.1016/B978-044452748-6.00176$0,2007$.

Wahr, J., Molenaar, M., and Bryan, F.: Time variability of the Earth's gravity field: Hydrological and oceanic effects and their possible detection using GRACE, J. Geophys. Res., 103, 205229, https://doi.org/10.1029/98JB02844, 1998.

Wahr, J., Swenson, S., and Velicogna, I.: Accuracy of GRACE mass estimates, Geophys. Res. Lett., 33, 1-5, https://doi.org/10.1029/2005GL025305, 2006.
Wal, W. V. D., Barnhoorn, A., Stocchi, P., Gradmann, S., Wu, P., Drury, M., and Vermeersen, B.: Glacial isostatic adjustment model with composite 3-D Earth rheology for Fennoscandia, Geophys. J. Int., 194, 61-77, https://doi.org/10.1093/gji/ggt099, 2013.

Wang, L., Shum, C. K., Simons, F. J., Tapley, B., and Dai, C.: Coseismic and postseismic deformation of the 2011 Tohoku-Oki earthquake constrained by GRACE gravimetry, Geophys. Res. Lett., 39, L07301, https://doi.org/10.1029/2012GL051104, 2012.

Whitehouse, P., Latychev, K., Milne, G. A., Mitrovica, J. X., and Kendall, R.: Impact of 3-D Earth structure on Fennoscandian glacial isostatic adjustment: Implications for space-geodetic estimates of present-day crustal deformations, Geophys. Res. Lett., 33, L13502, https://doi.org/10.1029/2006GL026568, 2006.

Whitehouse, P. L., Bentley, M. J., Milne, G. A., King, M. A., and Thomas, I. D.: A new glacial isostatic adjustment model for Antarctica: calibrated and tested using observations of relative sea-level change and present-day uplift rates, Geophys. J. Int., 190, 1464-1482, https://doi.org/10.1111/j.1365246X.2012.05557.x, 2012.

Wouters, B., Bonin, J. A., Chambers, D. P., Riva, R. E. M., Sasgen, I., and Wahr, J.: GRACE, time-varying gravity, Earth system dynamics and climate change, Reports on Progress in Physics, 77, 116801, https://doi.org/10.1088/0034-4885/77/11/116801, 2014.

$\mathrm{Wu}, \mathrm{P}$.: Sensitivity of relative sea levels and crustal velocities in Laurentide to radial and lateral viscosity variations in the mantle, Geophys. J. Int., 165, 401-413, https://doi.org/10.1111/j.1365246X.2006.02960.x, 2006.

Yu, Y., Chao, B. F., Garcia-Garcia, D., and Luo, Z.: Variations of the Argentine Gyre Observed in the GRACE Time-Variable Gravity and Ocean Altimetry Measurements, J. Geophys. Res.-Oceans, 123, 5375-5387, https://doi.org/10.1029/2018JC014189, 2018. 